\title{
ECONOMICS
}

\section{Urban Growth and Aggregate Growth in China}

\author{
by \\ Ning Ma \\ Hainan College of Economics and Business \\ Yanrui Wu \\ The University of Western Australia \\ and \\ Jianxin Wu \\ Jinan University
}




\title{
Urban Growth and Aggregate Growth in China
}

\author{
Ning Ma ${ }^{a, *}$, Yanrui $W^{b}$, Jianxin $W_{u^{c}}$ \\ ${ }^{a}$ Hainan College of Economics and Business \\ ${ }^{\mathrm{b}}$ The University of Western Australia \\ c Jinan University
}

\begin{abstract}
Using a spatial equilibrium model and data of 286 Chinese cities at the prefecture and above- prefecture level from 2002 to 2013, this study estimates the contribution of each of the selected Chinese cities to national GDP growth. The results in this study reveal several interesting patterns. First, what an individual city contributes to aggregate growth is not represented clearly by the city's GDP based on standard accounting calculation. Despite some of the strongest growth occurring in cities such as Beijing, Tianjin, Shanghai and Chongqing, these cities were only responsible for a small fraction of China's growth over the period covered. In fact, the analysis shows that it is growth in the cities in the west that has made the greatest contribution to the overall growth of China. Furthermore, the analysis of the results shows that the dispersion of the real wage across Chinese cities increased. This increased wage dispersion lowered aggregate Chinese GDP by 25.41 percent. This represents a loss, which is an effect of the tightening of regulatory constraints to housing supply in high productivity cities like Beijing, Tianjin, Harbin, Shanghai, Wuhan, Changsha, Chongqing, Chengdu, and Xian. Finally, a counterfactual scenario whereby these cities under regulatory constraints are reduced to the same level as the national mean level suggests that Chinese GDP would increase by 20.62 percent.
\end{abstract}

JEL Classifications: C6, O18, O53, R11, R31

Key Words: Spatial Equilibrium; Urban Growth; Welfare; China

*Corresponding author at: School of Financial Management, Hainan College of Economics and Business, No. 2 Xiaoji Rd, Hainan 570100, Hainan Province, PR China.

E-mail addresses: china_ma_ning@hotmail.com 


\section{Introduction}

China's rapid growth and increasing labour demand in urban areas has resulted in a historically unprecedented acceleration in urbanization. China experienced rural to urban migration to the tune of 275 million people between 1978 and 2014, which has resulted in widening income and wage disparity in urban China. For example, Figure 1 reveals that the distribution of relative wage has become more dispersed across Chinese cities between 2002 and 2013. The wage difference across cities reflects variation in labour productivity. Aggregate output may be increased by relocating labour to cities with higher productivity from cities with lower productivity. In contrast, aggregate output may be decreased if labour moves from high productivity cities to low productivity cities.

Local labour demand increase caused by an increase in local total factor productivity (TFP). This may drive aggregate output growth more effectively if the TFP increase results local labour supply increase. However, increases in local TFP have not translated to increases in local labour supply of the same scale for most China's western cities. Increases in local TFP in coastal cities tend to result in higher real wages and housing prices.

Specifically, this paper aims to investigate how the economic growth of 286 Chinese cities at the prefecture and above-prefecture levels (PAA) determines the growth of the nation. The analysis is based on the spatial equilibrium Rosen-Roback model, assuming that labour can move freely across Chinese cities. Local labour demand and supply cause the wage difference across Chinese cities. Local labour demand reflects local TFP, whereas local labour supply reflects local amenities and the housing supply.

The remainder of the paper begins with a brief review of the relevant literature in Section 2 . Section 3 describes the model, assumptions and data used for empirical analysis. Section 4 discusses wage dispersion in China and the empirical findings are presented in Section 5. 
Section 6 further decomposes the wage dispersion to consider amenities and the housing supply. Finally, Section 7 summarizes the findings and discusses potential policy implications.

Figure 1 Kernel Distribution of Relative Employment - Weighted Average Wage, 2002 and 2013

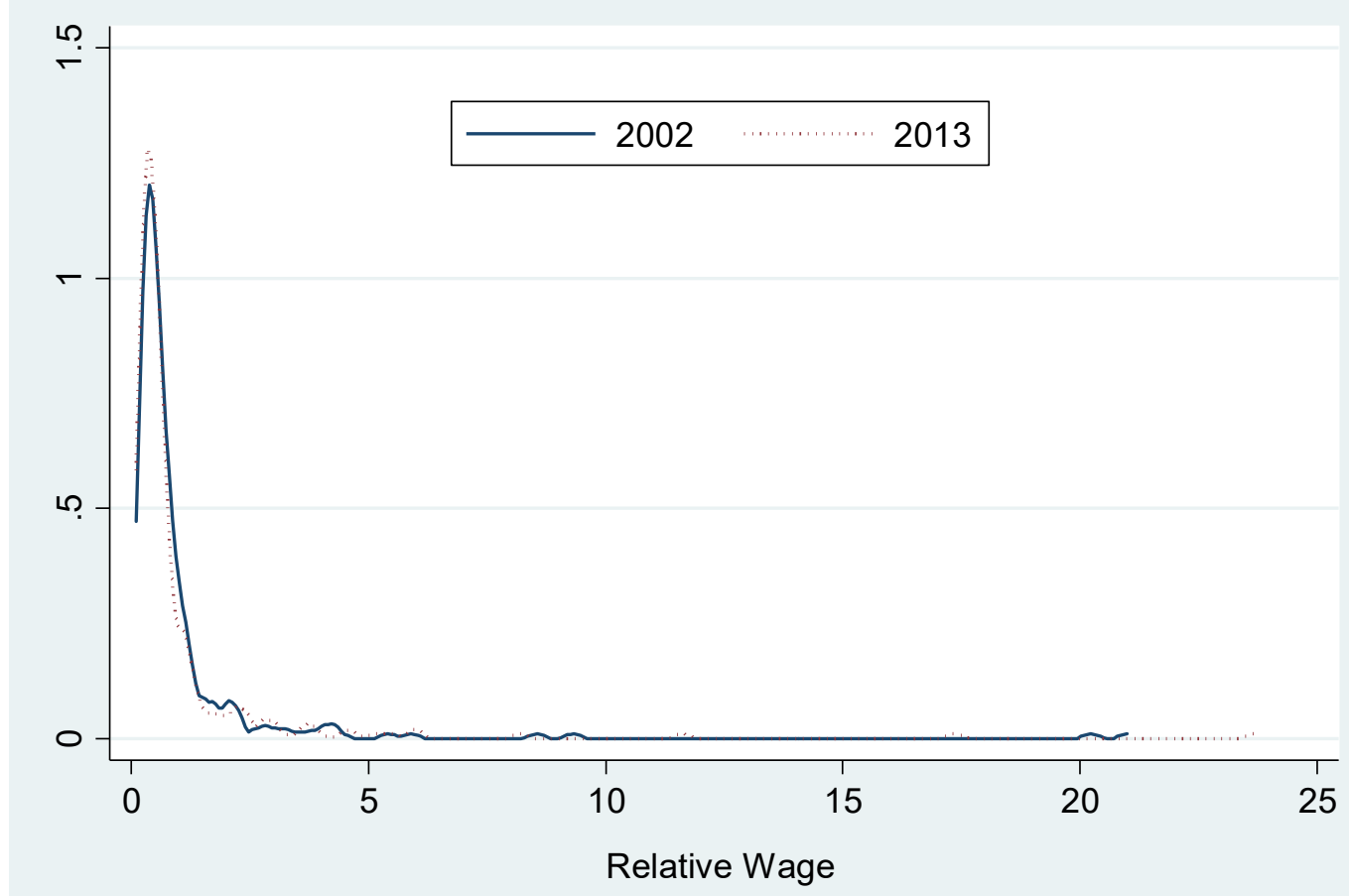

Source: Author's own calculations

\section{Literature Review}

A large body of literature on urban economics has indicated that local forces could explain the differences in wages across cities (for example, Barro et al. 1991; Barro and Martin 1992 and Gennaioli et al. 2012), but comparatively less attention has been paid to examine how local forces aggregate to affect a country's growth.

This study fills this gap, studying how the economic growth of cities has affected national growth. It examines 286 Chinese cities at the prefecture and above-prefecture (PAA) levels over the past decade and uses a spatial equilibrium model to address two questions. First, it 
estimates the contribution of individual Chinese city to national output growth between 2002 and 2013. Then, it presents a normative analysis of potential growth.

This paper contributes to the large body of empirical work begun by Rosen (1979) and Roback (1982). There exists a significant body of literature which uses price data on rent and wages to estimate differences in amenities, technology levels and housing supply regulations across cities (Chatterjee and Carlino 2001; Rappaport 2007 and Redding and Sturn 2008). This study highlights the aggregate negative impact of housing supply regulations and changes on amenities, and is most closely related to Au and Henderson (2006), Desmetes and RossiHansberg (2013), Redding (2016) and Hsieh and Moretti (2017). Au and Henderson (2006) employ a model with agglomeration economies and congestion effects to analyse optimal size of Chinese cities, while Desmetes and Rossi-Hansberg (2013) analyse the effect of the heterogeneity of local TFP, amenities and local frictions in the US and China. Hsieh and Moretti (2017) estimate the contribution of 220 US cities to national GDP by use a spatial equilibrium model. Redding (2016) analyses the effect of internal trade frictions on welfare. This paper focuses on the effect of amenities and housing supply on wage dispersion and aggregate output in China.

\section{Model, Assumptions and Data}

\subsection{Model}

This study uses a standard spatial equilibrium Rosen-Roback model. The spatial equilibrium hypothesis has been the organizing principle of urban economics for over fifty years, and thus is suitable for this context. It was first applied to land prices and usages within metropolitan areas by Alonso (1964) and Muth (1969) and then was extended to income and price differences across metropolitan areas by Rosen (1979) and Roback (1982). Since then, several studies have applied the Rosen and Roback model to examine the effect of local regulations of 
land use on local housing prices (for example, Glaeser et al. 2005; Glaeser and Gyourko 2005 and Saiz 2010).

The core idea of the spatial equilibrium Rosen-Roback model is that cities do not offer a 'free lunch'. For example, if a city has nice amenities, then local real wages are expected to be lower due to a larger labour supply, if a city has higher wages and better amenities, then local house prices are expected to be high (Chauvin et al. 2017).

City $i$ 's technology level can be expressed as follows:

$$
Y_{i}=A_{i} L_{i}^{\alpha} K_{i}^{\eta}
$$

Here, $Y_{i}$ denotes real gross regional product, $A_{i}$ is TFP, $L_{i}$ is employment, and $K_{i}$ is the capital stock.

Assume labour can move freely across cities and has indirect utility given by:

$$
V=\frac{W_{i} Z_{i}}{P_{i}^{\beta}}
$$

where $W_{i}$ denotes the real wage, $Z_{i}$ represents amenities, $P_{i}$ is the housing price in the city and $\beta$ is the share of expenditure on housing. ${ }^{1}$ It assumes that capital is supplied with infinite elasticity at an exogenously given housing price (Hsieh and Moretti 2017).

Now, the equilibrium labour allocation across cities may be displayed as (see Appendix E for the solution of the model):

\footnotetext{
${ }^{1}$ This study calculates the share of housing expenditures based on data from the China Statistical Yearbook. It uses national household expenditures on housing divided by national household total expenditures. Here it suggests that $\beta$ is roughly constant across the 286 Chinese cities.
} 


$$
L_{i}=\left(\alpha^{1-\eta} R_{i}^{-\eta} \eta^{\eta}\right)^{\frac{1}{1-\alpha-\eta}}\left(\frac{A_{i}}{W_{i}^{1-\eta}}\right)^{\frac{1}{1-\alpha-\eta}}
$$

where, $\eta A_{i} L_{i}^{\alpha} K_{i}^{\eta-1}=R_{i}$, which denotes the interest rate. Labour demand is increasing if local TFP increasing and decreasing if the local real wage increasing. This has been confirmed by numerous empirical studies, for example, Desmet and Rossi-Hansberg (2013). By substituting (2) into (3), it is possible to see that employment can also be expressed as $L_{i}=\left(\alpha^{1-\eta} \frac{\eta}{R_{i}}\right)^{\frac{1}{1-\alpha-\eta}} V^{\frac{1}{1-\alpha-\eta}}\left(\frac{A_{i} Z_{i}^{1-\eta}}{P_{i}^{\beta(1-\eta)}}\right)^{\frac{1}{1-\alpha-\eta}}$. Higher labour supply in cities may be due to high local TFP, low housing prices and better amenities.

This model assumes $P_{i}=L_{i}^{\gamma_{i}}$, where $\gamma_{i}$ is a parameter measuring the elasticity of the housing supply with respect to the number of workers. An increase in the number of workers also increase the local house prices when $\gamma_{i}$ is large. Land availability and land use restrictions could affect $\gamma_{i}$ across cities. $\gamma_{i}$ is higher if cities have stringent land use restrictions and $\gamma_{i}$ is lower if cities have abundant land and relaxed land use regulations (Glaeser et al., 2005).

The equilibrium wage is now written as:

$$
W_{i}=\left(V\left(\frac{\eta \alpha^{1-\eta}}{R_{1}}\right)^{\frac{\gamma_{i} \beta}{1-\alpha-\eta}}\right)^{\frac{1}{(1-\eta)\left(1+\beta \gamma_{i}\right)-\alpha}}\left(\frac{A_{i}^{\beta \gamma_{i}}}{Z_{i}^{1-\alpha-\eta}}\right)^{\frac{1}{(1-\eta)\left(1+\beta \gamma_{i}\right)-\alpha}}
$$

This equation implies that the equilibrium wage depends on $\gamma_{i}$ and is increasing with local TFP and decreasing with local amenities. TFP reflects labour demand; that is, higher local TFP implies stronger local labour demand and therefore higher local real wages, and vice versa. Amenities and housing supply reflect labour supply. For example, desirable amenities imply a larger labour supply and therefore lower real local wages. Workers will be more willing to live in a city that has better amenities, even if the local real wage is lower. 
Next, it is possible to solve for aggregate output and welfare. First, equations (2) and (3) are used to express welfare as:

$$
V=Y\left(\sum_{i} \frac{L_{i} P_{i}^{\beta}}{Z_{i}}\right)^{-1}
$$

where $Y=\sum_{i} Y_{i}$ denotes aggregate output. $\sum_{i} \frac{L_{i} P_{i}^{\beta}}{Z_{i}}$ is the price of utility. Second, it is assumed that aggregate labour demand is equal to aggregate labour supply, then aggregate output can be expressed as follows:

$$
Y=\frac{\left(\frac{\eta \alpha^{1-\eta}}{R_{i}}\right)^{\frac{1}{1-\eta}}}{\alpha}\left(\sum A_{i}^{\frac{1}{1-\alpha-\eta}}\left(\frac{\bar{W}}{W_{i}}\right)^{\frac{1-\eta}{1-\alpha-\eta}}\right)^{\frac{1-\alpha-\eta}{1-\eta}}
$$

where $\bar{W}=\sum_{i} W_{i} L_{i}$ stands for the employment-weighted average real wage and $W_{i}$ is solved by equation (4). Aggregate output depends on local TFP and the city's average real wage relative to the national mean level. Housing supply elasticity $\gamma_{i}$ could affect housing price and then housing price could affect aggregate output by changing the local real wages The growth of aggregate output can be defined as: 


$$
\begin{aligned}
& \frac{Y_{t+1}}{Y_{t}}=\frac{\left[\sum A_{i, t+1}^{\frac{1}{1-\alpha-\eta}}\left(\frac{\bar{W}_{t+1}}{W_{i, t+1}}\right)^{\frac{1-\eta}{1-\alpha-\eta}}\right]^{\frac{1-\alpha-\eta}{1-\eta}}}{\left[\sum A_{i, t}^{\frac{1}{1-\alpha-\eta}}\left(\frac{W_{t}}{W_{i, t}}\right)^{\frac{1-\eta}{1-\alpha-\eta}}\right]^{\frac{1-\alpha-\eta}{1-\eta}}}
\end{aligned}
$$

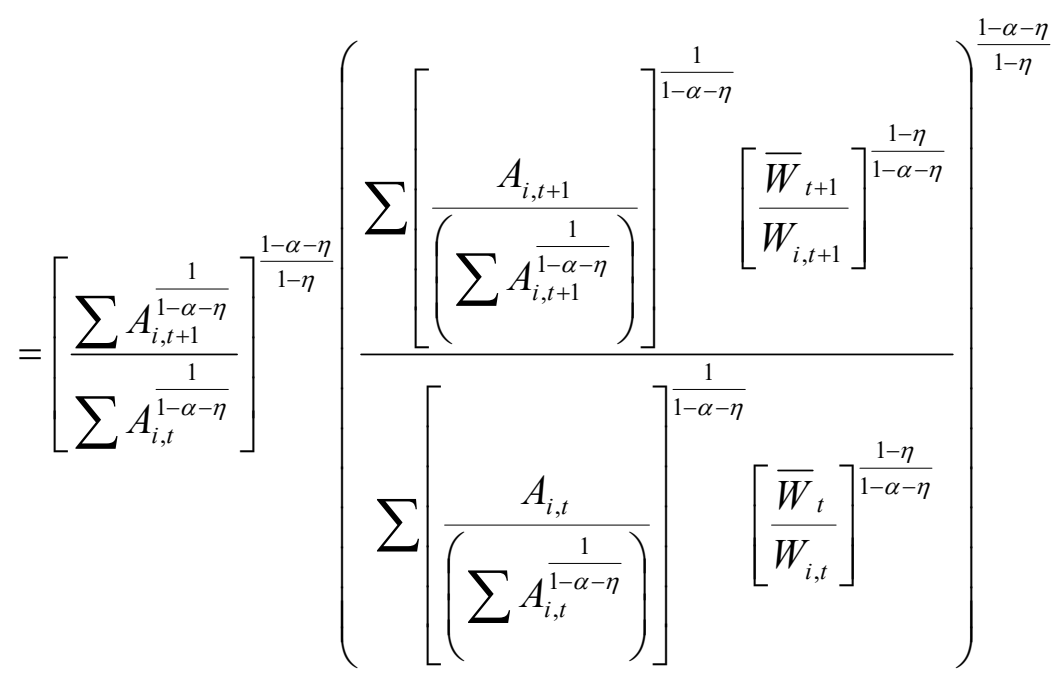$$
=\left[\frac{\sum A_{i, t+1}^{\frac{1}{1-\alpha-\eta}}}{\sum A_{i, t}^{\frac{1}{1-\alpha-\eta}}}\right]^{\frac{1-\alpha-\eta}{1-\eta}}\left(\frac{\sum S_{i, t+1}\left[\frac{\bar{W}_{t+1}}{W_{i, t+1}}\right]^{\frac{1-\eta}{1-\alpha-\eta}}}{\sum S_{i, t}\left[\frac{\bar{W}_{t}}{W_{i, t}}\right]^{\frac{1-\eta}{1-\alpha-\eta}}}\right)^{\frac{1-\alpha-\eta}{1-\eta}}
$$

where $S_{i}=\frac{A_{i}^{\frac{1}{1-\alpha-\eta}}}{\sum A_{i}^{\frac{1}{1-\alpha-\eta}}}$ denotes the hypothetical city size when real wages are identical across all cities. Equation (7) indicates that aggregate output growth can be decomposed into two effects which are the effect of local TFP and the effect of a change in the spatial dispersion of wages. Those two forces also would determine the growth of aggregate welfare, as well as changes in the price of utility.

To explain these mechanisms, it needs to consider how changes in local TFP and local amenities affect aggregate output and welfare (Hsieh and Moretti 2017). Firstly, higher TFP growth in cities results in higher aggregate output and welfare (holding the price of utility 
constant). Higher local TFP raises the local labour supply and results in higher housing prices. This increases the average housing price in all cities and lowers welfare (holding aggregate output fixed), and this effect is larger when the local housing supply is relatively inelastic. Secondly, high local housing prices increase the local average real wage, but the effect of the increased local wage on aggregate output depends on whether the city's wage is higher or lower than the national average. If there is an increase in the local housing price in cities with higher wages, which expand the gap between the local wage and the average national wage, aggregate welfare will fall. However, TFP increase in a city with lower wages could result in an increase in local wages, and it will narrow the gap between the local wage and the average national wage, which would increase aggregate welfare. In this case, the growth rate of cities with low wages understates the local contribution to aggregate output growth.

Furthermore, declines in local TFP will decrease aggregate output and welfare. In the framework, a decline in local TFP will lower the local housing price and lower local housing prices have two different effects. Firstly, lower housing prices lower the price of utility, which increases aggregate welfare. Secondly, lower housing prices also lower the local real wage, and the aggregate effect depends on the level of the local wage relative to the national average real wage. If the local real wage is higher than the national average, a decrease in the real wage potentially narrows the wage gap, and it increases aggregate welfare. Under this scenario, local GDP decreases due to the effect of the decrease in local TFP and the decrease in the local wage. However, there could be a positive net effect on aggregate output growth if the effect of the narrowing wage gap is larger than the effect of the decrease in local TFP.

Finally, if amenities improve in high wage cities, this increases the aggregate level of amenities and narrows the wage gap. Based on the model, the decline in wage dispersion improves welfare, and increases the contribution of local output (welfare) to aggregate output (welfare). In contrast, if amenities improve cities with lower local wage, it will increase the aggregate 
level of amenities, but it will also expand the wage gap. In this case, although local GDP increases, but the improvement of amenities in lower wage cities would lower aggregate output (Hsieh and Moretti 2017).

This study uses the logic above as a framework for two calculations in the empirical analysis. First, it measures the contribution of each Chinese city to aggregate Chinese growth. Second, it calculates the counterfactual output growth in China under different assumptions regarding wage dispersion.

\subsection{Assumptions and Extensions}

To begin with, three assumptions are made for this study: (i) TFP and amenities are exogenous; (ii) workers do not own housing stock, and (iii) workers have homogeneous tastes and are perfectly mobile across cities. All three assumptions can be relaxed below.

\section{TFP and amenities are exogenous:}

A significant body of literature on urban economics indicates that the level of TFP and amenities might not be exogenous, but rather may depend on city size (Ahlfeldt et al. 2015 and Diamond 2017). In this study it is assumed that the elasticity of agglomeration and amenities are constant across cities, so that worker mobility and relocation across cities has no aggregate impact on aggregate TFP and amenities. This is due to the changes experienced by cities that grow are exactly offset by changes experienced by cities that shrink.

\section{Workers do not own housing stock:}

Under this assumption, housing market booming lowers welfare if workers do not own the housing stock in particularly city. Suppose, instead, it is assumed that the housing stock is owned by workers in equal proportions. All the equations remain the same, except that welfare is now given by: 


$$
V=\left(Y+\sum_{i} L_{i} h_{i} P_{i}\right)\left(\sum_{i} \frac{L_{i} P_{i}^{\beta}}{Z_{i}}\right)^{-1}
$$

where $h_{i}$ denotes housing consumption per capita. This means that welfare will affected by housing prices through the effect of the dispersion of real wages on aggregate output.

The most realistic case in China is that workers own housing stock in the city in which they reside. In other words, workers in some areas are made better off due to the increasing of local housing price, while workers in other areas become worse off due to the decline of local housing price. However, in aggregate level, the conclusions for this study are identical under the assumption of the housing stock is owned by workers in equal proportions.

\section{Workers have homogeneous tastes over locations and are perfectly mobile across cities:}

In reality, mobility is possible but imperfect in China due to the Hukou system. Thus, the indirect utility of workers becomes $V=Y\left(\sum_{i} \frac{L_{i}^{1+\frac{1}{\theta}} P_{i}^{\beta}}{Z_{i}}\right)^{-1}$. This equation indicates that indirect utility will differ across cities depending on the workers' preferences, $\theta$, even if housing prices and amenities are the same across all cities. However, even if different workers have different utility, average utility is still the same in all cities. It can be concluded that estimated aggregate output remains unchanged and does not depend on 6 .

\subsection{Data}

There were 288 PAA cities in China by the end of 2014. However, most of the data are not available for two cities in Tibet (Lasa and Rikaze). Therefore, this paper uses a panel data set encompassing 286 cities, between 2002 and 2013. These data were obtained from the China City Statistical Yearbooks, China Statistical Yearbook, and Wind Financial Terminal (WFT). In particular, there is a focus on the following variables: city GDP, labour (city employees at 
the end of the year), capital stock, city annual average wage per capita, and city average housing price. The variables for capital stock (see Appendix A for calculation details), city annual average wage per capita and GDP are deflated by the consumer price index (CPI) in 2000 constant prices. The estimate for labour share, $\alpha$ is 0.43 and the estimate for capital share $r$ is 0.39 , although sensitivity analysis is also provided using different values of $\alpha$ and $\eta$. $^{2}$

Average housing prices are available for each city, but average rental price data is not available. Cities' average rental price is estimated by using the product of average housing price and the annual nominal deposit rate for that year (Ren et al. 2012). ${ }^{3}$

The housing expenditure share $\beta_{i}$ is calculated as the ratio of average household housing expenditures to average household total expenditures. Housing supply elasticity, $\gamma_{i}$, is also required for each city, and the calculation details can be found in Appendix D.

\section{Changes in the Spatial Dispersion of Real Wages, $2002-2013$}

The model indicates lower aggregate output resulted by larger wage dispersions, holding other things constant. Wages reflect the labour productivity of city, and thus, aggregate output may be increased by reallocating some workers from areas with low productivity to areas with high productivity. For instance, in 2013, average real wages per capita in Beijing and Shanghai were more than three times larger than real wages in Yichun and Xiangfan, as the labour productivity in Beijing and Shanghai is more than three times as large. If some workers were reallocated from Yichun and Xiangfan to Beijing, aggregate GDP would increase as there would be an

\footnotetext{
${ }^{2}$ We estimate $\alpha$ and $\eta$ by using on the function $\ln ($ GDP $)=\varphi+\alpha \ln$ (Labour) $+\eta \ln$ (Capital Stock) $+\varepsilon$

${ }^{3}$ The nominal deposit rate is a one-year fixed term deposit rate, obtained from The People's Bank of China. The average nominal deposit rate over the period was 2.3 per cent. Wu et al., (2012) estimated the rent-to-price ratio to be $2-3$ per cent, which is consistent with this study.
} 
increase in workers in a city that is highly productive. In principle, aggregate output is maximized when wages are equalized across cities.

Empirically, real wages across Chinese cities are more spatially dispersed in 2013 than in 2002, which suggest a negative effect on output growth. Figure 2 and Table 1 show the change in the dispersion of average real wages. Figure 2 reveals that the mean levels of real wage per capita have increased for all three regions from 2002 to 2013. As expected, the Kernel distributions of real wages for all three regions have become much wider, especially for western cities. Panel A of Table 1 indicates that the standard deviation, interquartile range, and the range (difference between maximum and minimum value) of the average real wage per capita have all increased from 2002 to 2013. Panel B shows that this increase in dispersion is driven by four cities with high real wage levels over the past decade: Beijing, Shanghai, Guangzhou and Shenzhen. Excluding these four cities significantly affect the wage distribution. The standard deviation and the range of the average real wage are much smaller when these four large cities are excluded. 
Figure 2 Spatial Dispersion of Real Wages in 2002 and 2013, by Regions

\section{Coastal Cities}

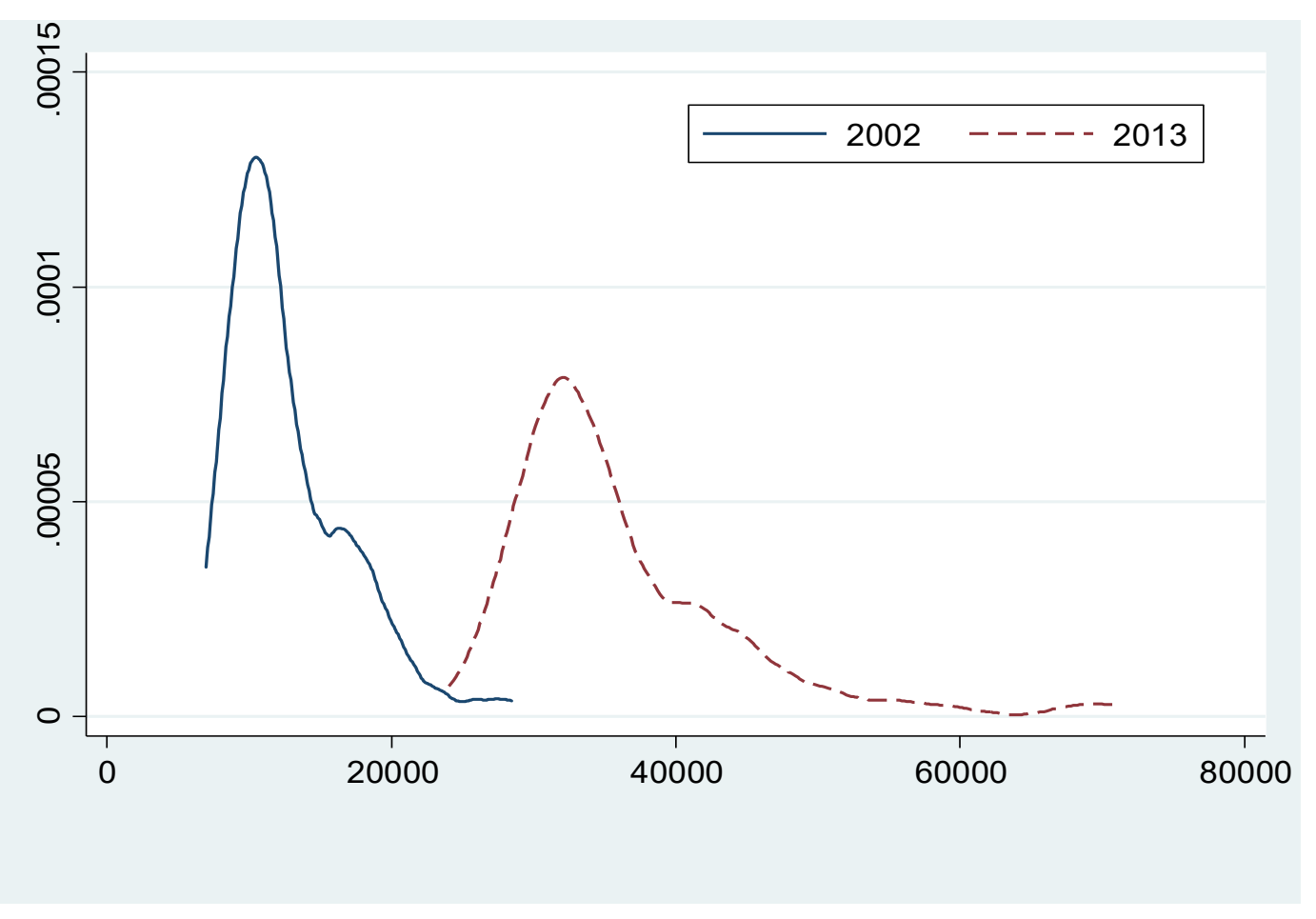

\section{Central Cities}

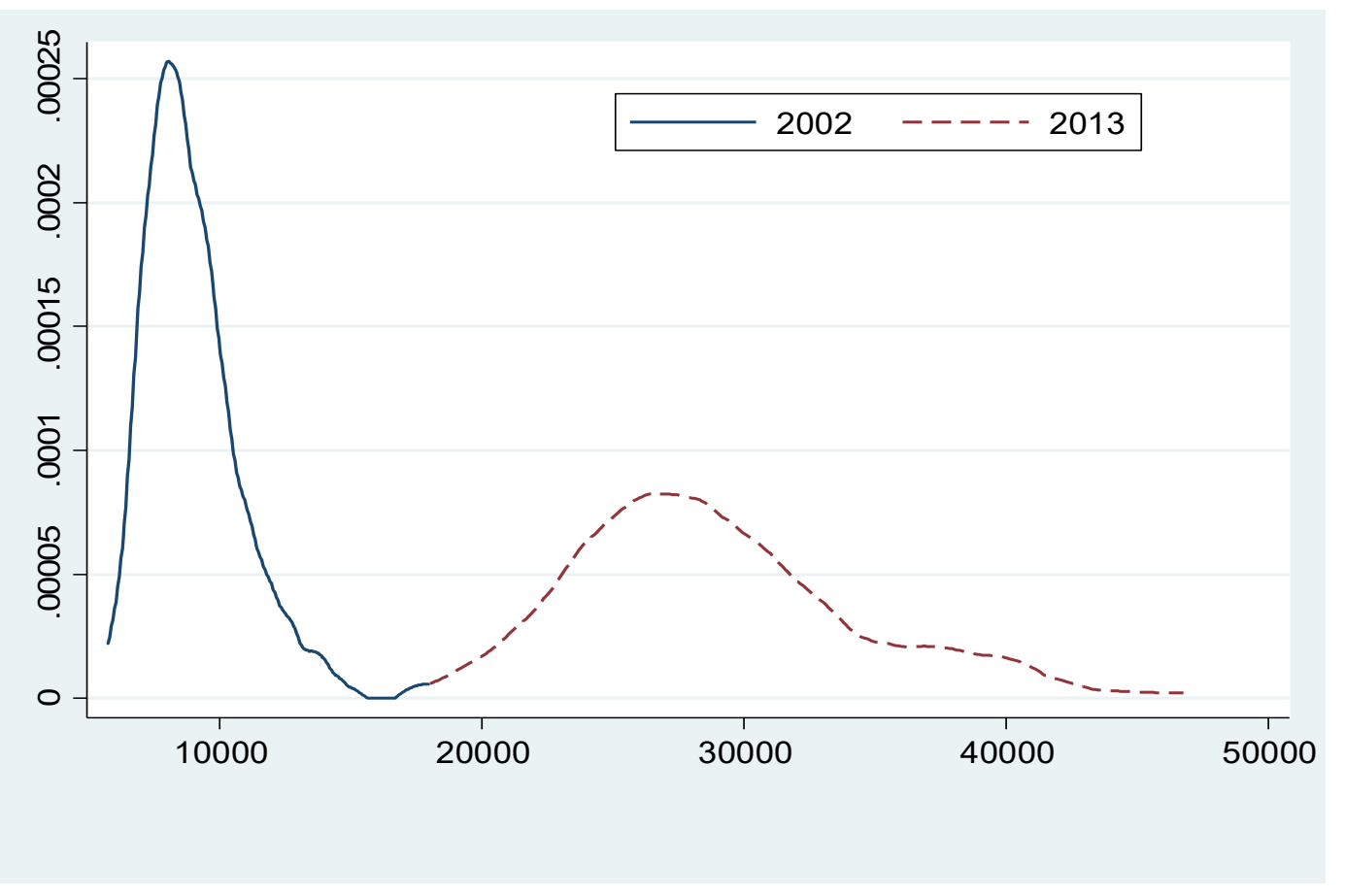




\section{Western Cities}

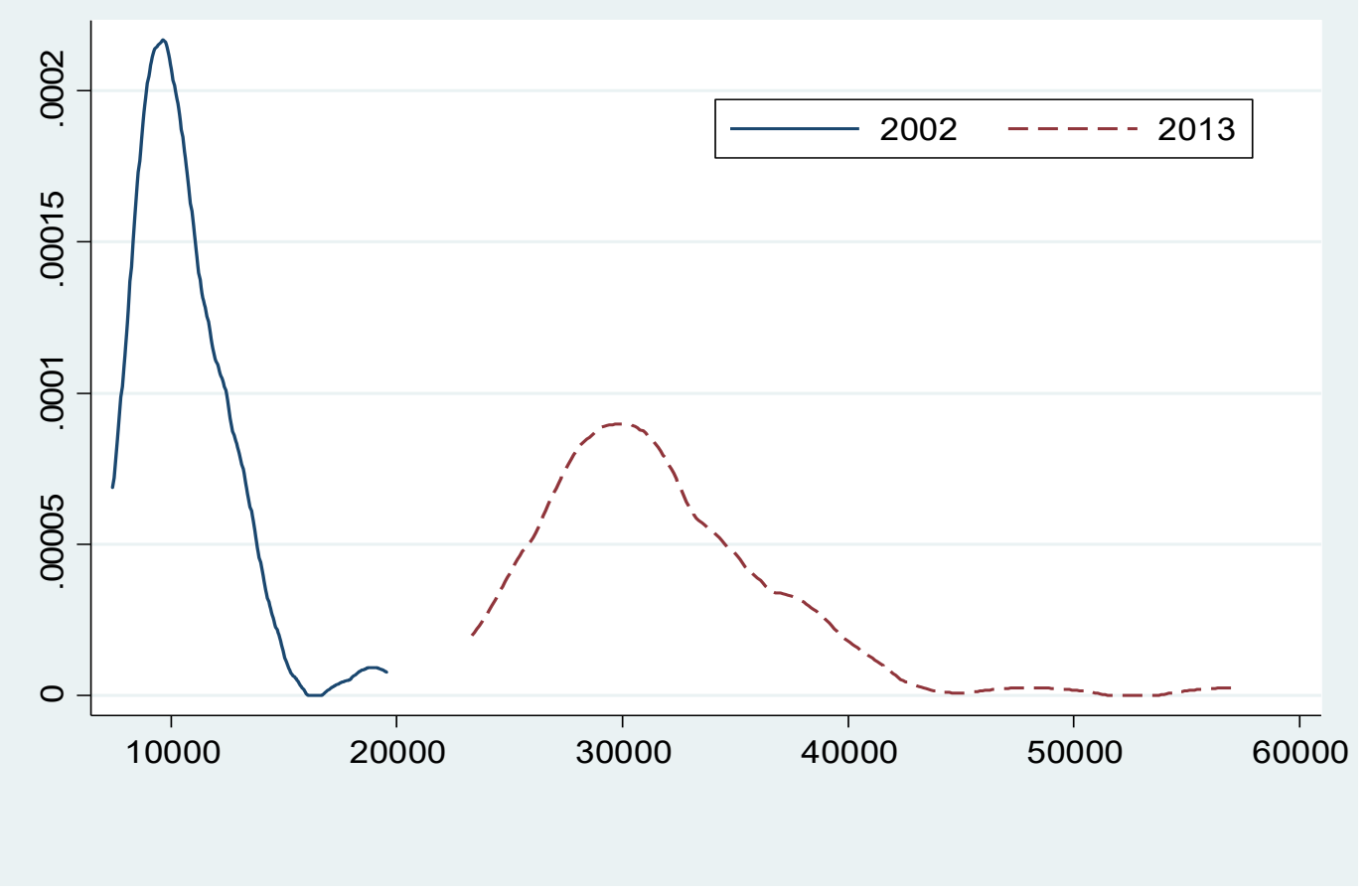

Source: Author's own calculations

Table 1 Spatial Dispersion of Real Wages in 2002 and 2013

\begin{tabular}{|l|c|c|c|}
\hline & Std. Dev. & Interquartile & Range \\
\hline Panel A: All Cities & (1) & (3) \\
\hline Log Wage in 2002 & 0.37 & 0.43 & 2.34 \\
\hline Log Wage in 2013 & 0.40 & 0.45 & 2.39 \\
\hline Panel B: Excluding Beijing, & & & \\
\hline Shanghai, Guangzhou, Shenzhen & & & \\
\hline Log Wage in 2002 & 0.33 & 0.41 & 1.79 \\
\hline Log Wage in 2013 & 0.36 & 0.41 & \\
\hline
\end{tabular}

Source: Author's own calculations

Notes: All figures are weighted by employment in the relevant city 


\section{Empirical Findings}

First, the adjusted contributions of each Chinese city toward aggregate growth are calculated and compared with the city's GDP growth as a percentage of aggregate GDP growth over the same period (Section 5.0). Second, a counterfactual calculation is performed to see how much larger China's GDP would be if the spatial dispersion of wages was identical for year 2002 and 2013 (Section 6.0).

\subsection{Local and Aggregate Growth}

Equation (7) is used to calculate the adjusted contribution of each city to aggregate growth, from 2002 to 2013. These calculations are presented in Table 2 and Figures 3 - 6, with the contribution of three groups (regions) of cities shown separately. Figure 3 displays the adjusted contribution of the 286 Chinese cities to aggregate growth against the accounting contribution of local GDP to aggregate GDP growth over the examined period. The calculation of adjusted contribution is based on the model, equation (7), whereas the accounting contribution indicates the growth in local GDP as a ratio of aggregate GDP growth. ${ }^{4}$ Cities that lie above the solid 45-degree line show that they have a higher adjusted contribution than the accounting contribution, while cities below the solid line shows that they have a higher accounting contribution than the adjusted contribution. According to the results, 119 cities have a higher accounting contribution than the adjusted contribution.

The first feature apparent from Figure 3 is that the dispersion of the accounting contribution of each city is much wider than that of the adjusted contribution. The range of the accounting

4 The 'accounting contribution' calculation of local growth is based on the accounting identity $\frac{y_{i, t+1}}{y_{i, t}} L_{i, t} / \sum_{i=1}^{286} \frac{y_{i, t+1}}{y_{i, t}} L_{i, t}$, where the $t$ and $t+1$ subscripts denote time, $y_{i}$ is GDP per worker in city $i$, and $L_{i}$ is the employment share in city $i$. The contribution of local to aggregate is the ratio between local growth and aggregate growth. 
contribution is 3.90 per cent, whereas the range (the difference between the maximum and the minimum value) of the adjusted contribution is only 1.10 per cent.

Another feature of Figure 3 is that there are sizeable differences between the two estimated contributions. For example, Beijing's GDP growth was 4.00 per cent of aggregate output growth from 2002 to 2013. However, based on the Rosen-Roback model, Beijing was only responsible for 1.00 per cent of aggregate output growth. This difference is likely due to the fact that output growth of Beijing was driven by higher real wages and higher housing prices, which increased the overall spatial misallocation of labour. As an alternate example, Yulin's GDP growth was 0.71 per cent of aggregate output growth from 2002 to 2013, while its adjusted contribution was 3.01 per cent. In the case of Yulin, the difference is because much of the adjusted growth was driven by TFP improvements. Other cities display significant differences, such as Zhongwei and Jiayuguan, which are both well above the solid line.

\section{Figure 3 Accounting Contribution and Adjusted Contribution - Overall}

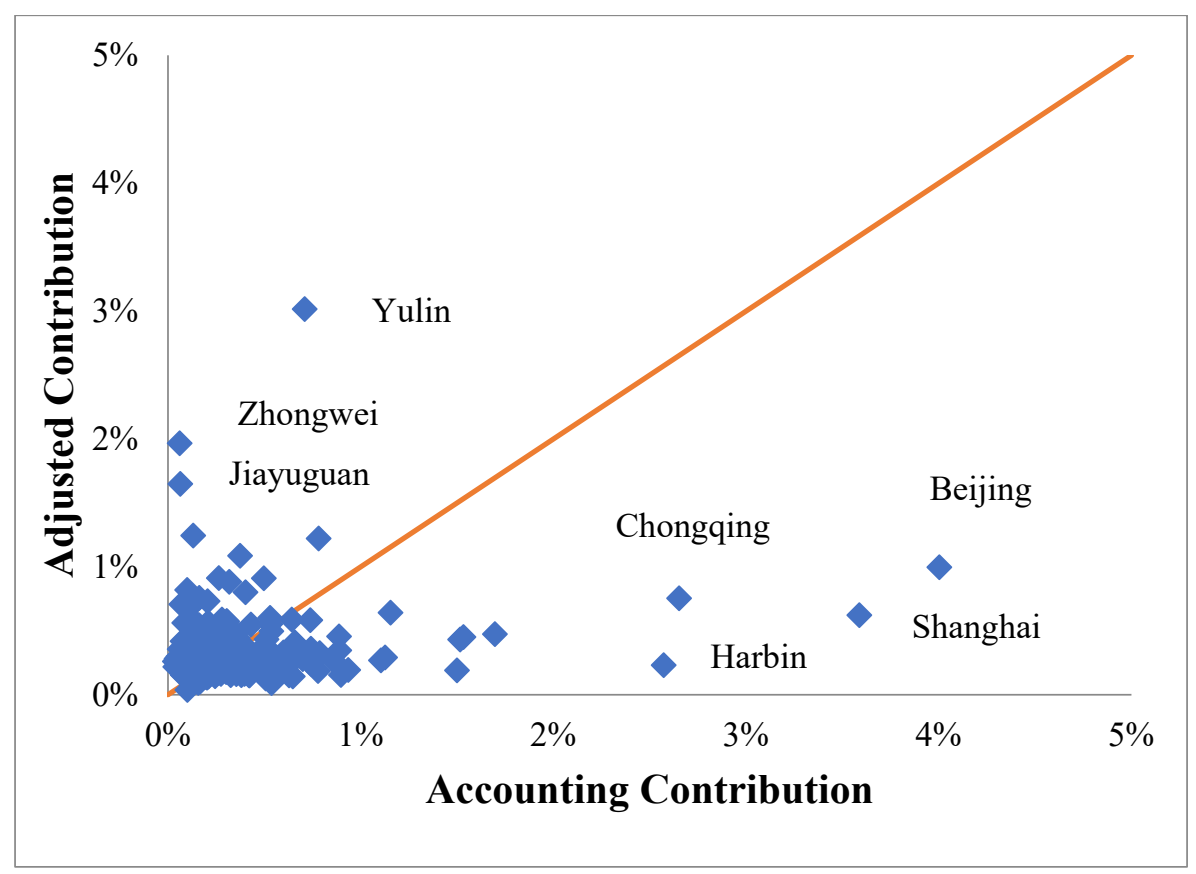

Source: Author's own calculations 
Overall, Figure 3 shows that the relationship between the local accounting contribution to aggregate growth and the local adjusted contribution to aggregate growth is positive, but with an elasticity far below one. A regression of the variable of adjusted contribution on the variable of accounting contribution yields a coefficient (standard error) of $0.10(0.02)$, with an intercept equal to 0.003 .

Figures $4-6$ present the contribution of cities in three regional groups. Figure 4 shows the adjusted contribution against the accounting contribution of coastal cities and 58 coastal cities lie above the 45-degree line. However, four large cities - Beijing, Shanghai, Tianjin and Shenyang - lie significantly below the 45-degree line. Although local output grew rapidly in all four cities, but the wage gap between those cities and national level is large.

Figure 4 Accounting Contribution and Adjusted Contribution - Coastal Cities

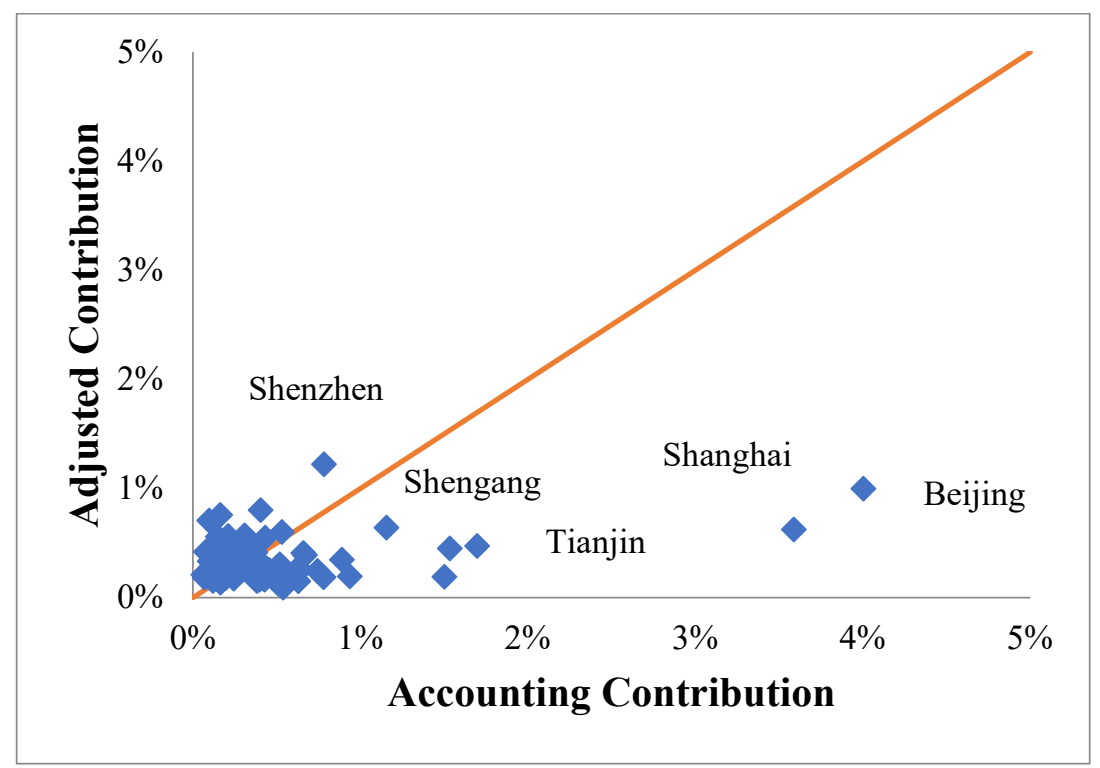

Source: Author's own calculations

Figures 5 and 6 shows the contributions of 101 and 84 cities in the central and western areas, respectively. As shown, most of the central and western cities lie above the 45-degree line, which mean adjusted contribution of these cities is larger than accounting contribution. This discrepancy is driven by real wages in central regions having narrowed the wage gap, and 
because TFP in western regions has been grown rapidly. More surprisingly, though local GDP growth is much lower in western cities than coastal cities, the adjusted contribution of western cities to aggregate growth is larger than that of coastal cities.

Figure 5 Accounting Contribution and Adjusted Contribution - Central Cities

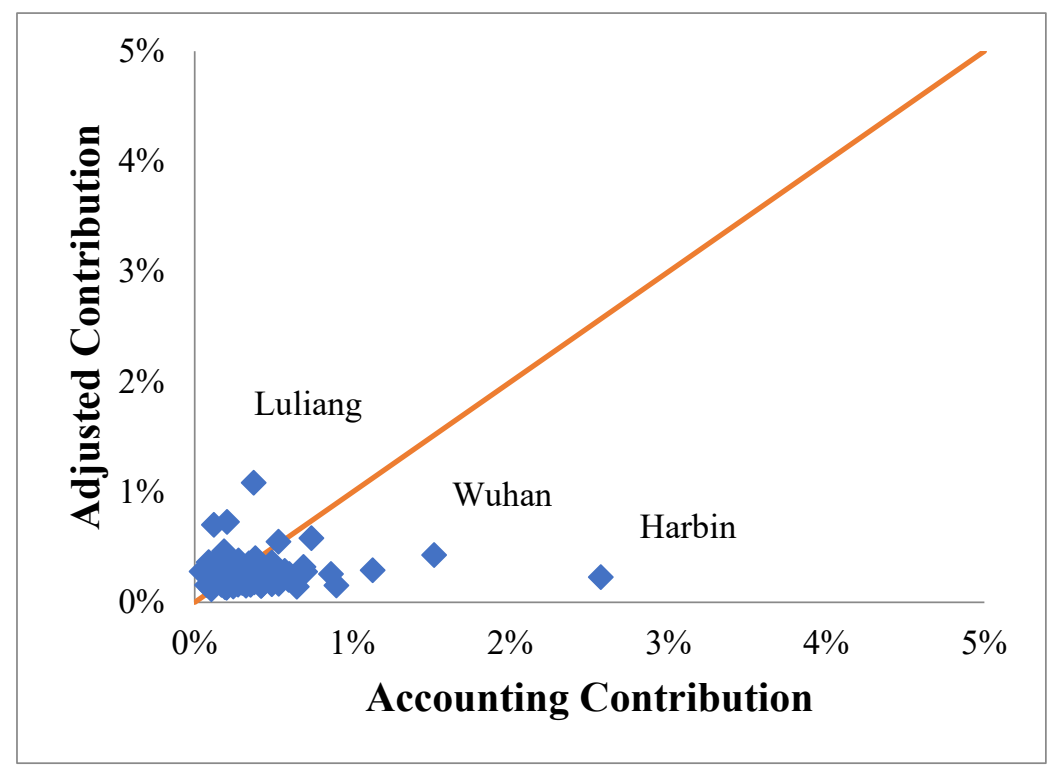

Source: Author's own calculations

Figure 6 Accounting Contribution and Adjusted Contribution - Western Cities

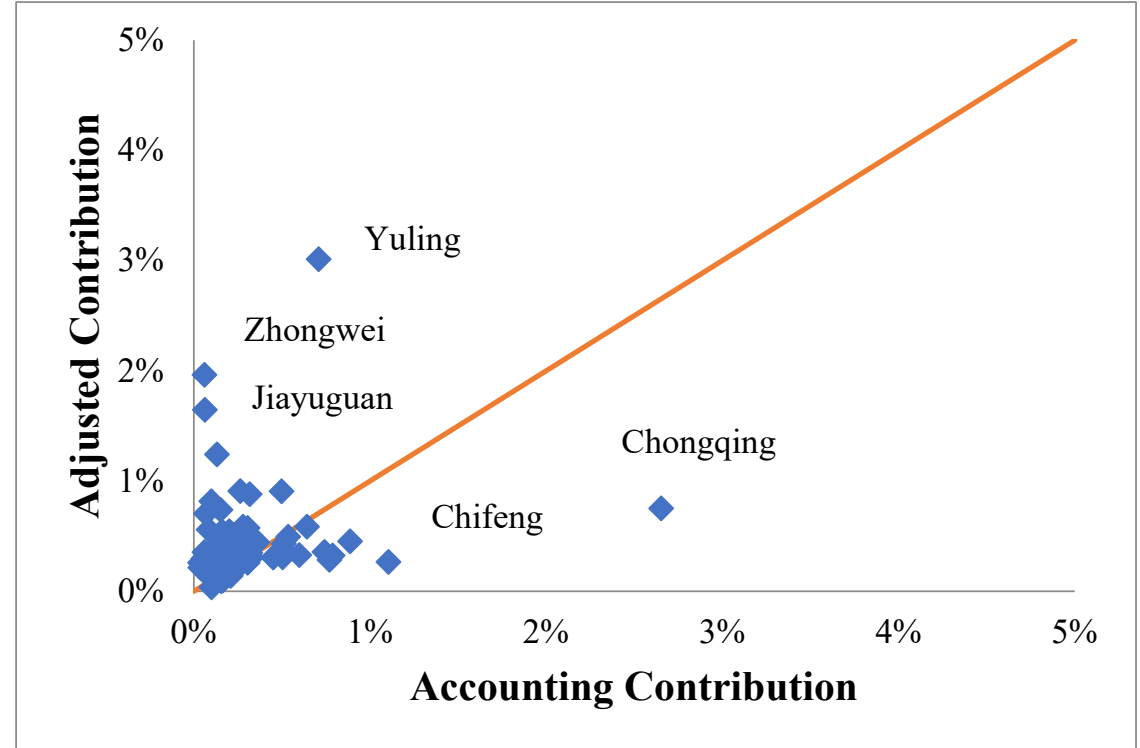

Source: Author's own calculation 
Table 3 provides a robustness check for our estimates, using different assumptions on technology level. To obtain the different labour and capital shares, the table input draws on $\mathrm{Wu}$ (2001) and Zhu (2012). Recall that our baseline parameters are $\alpha=0.43$ and $\eta=0.39$ for all cities in years 2002 and 2013. In columns 2 and 3, returns to scale are the same and $\alpha$ and $\eta$ are varied.

Table 2 Accounting Contribution and Adjusted Contribution by Group

\begin{tabular}{|l|l|l|}
\hline & Accounting Contribution & Adjusted Contribution \\
\hline Coastal Cities (N=101) & $42.82 \%$ & $34.74 \%$ \\
\hline Central Cities (N=101) & $33.95 \%$ & $27.78 \%$ \\
\hline Western Cities (N=84) & $23.23 \%$ & $37.48 \%$ \\
\hline
\end{tabular}

Source: Author's own calculations

Table 3 Adjusted Contribution by Group - Robustness Check

\begin{tabular}{|l|l|l|l|}
\hline & \multicolumn{1}{|c|}{ (1) } & (2) & \multicolumn{1}{|c|}{ (3) } \\
& Baseline & & \\
Adjusted Contribution & $\begin{array}{l}\alpha=0.43 \\
\eta=0.39\end{array}$ & $\begin{array}{l}\alpha=0.32 \\
\eta=0.5\end{array}$ & $\begin{array}{l}\alpha=0.5 \\
\eta=0.32\end{array}$ \\
\hline Coastal Cities (N=101) & $34.74 \%$ & $35.83 \%$ & $34.18 \%$ \\
\hline Central Cities (N=101) & $27.78 \%$ & $22.91 \%$ & $29.99 \%$ \\
\hline Western Cities (N=84) & $37.48 \%$ & $41.26 \%$ & $35.83 \%$ \\
\hline
\end{tabular}

Source: Author's own calculation 


\section{Wage Dispersion and Aggregate Growth}

Equation (7) shows that there are two effects on aggregate growth which are the effect of local TFP and the effect of change in the spatial dispersion of wages. The equation shows that increased wage dispersion negatively affects aggregate growth. Empirically, the spatial dispersion of real wages across Chinese cities increased between 2002 and 2013.

This section examines the effect of wage dispersion on aggregate output growth between 2002 and 2013. It estimates counterfactual output by assuming that the relative wage of a city in 2002 and 2013 are identical. It takes local TFP in each city as fixed. Change in the local housing supply and amenities would reflect labour and capital reallocation (Hsieh and Moretti 2017). As evident from equation (4), local wages are determined by local TFP, amenities and the elasticity of housing supply.

Figure 7 shows that if the relative wage dispersion had not changed, 163 Chinese cities (mostly in the west) would have had higher growth. Based on this result, holding local TFP constant, the increased spatial dispersion of wages lowered aggregate GDP growth by 25.41 per cent from 2002 to 2013. Table 4, assumes that the distribution of real wages in 2013 is equal to the 2002 level for all cities, coastal cities, central cities and western cities. The results show that all cities would have grown more if the real wage level of 2013 was equal to that in 2002 . For example, given that China's GDP in 2013 was 9.24 trillion USD, this would imply an additional annual aggregate income of 2.35 trillion USD.

Table 5 shows the robustness of the estimation under different scenarios. It is founded that the results are not sensitive to changes in labour and capital shares for a given degree of returns to scale. 
Figure 7 Counterfactual Output and Adjusted Output - The Effect of Changes in the Spatial Dispersion of Relative Wages

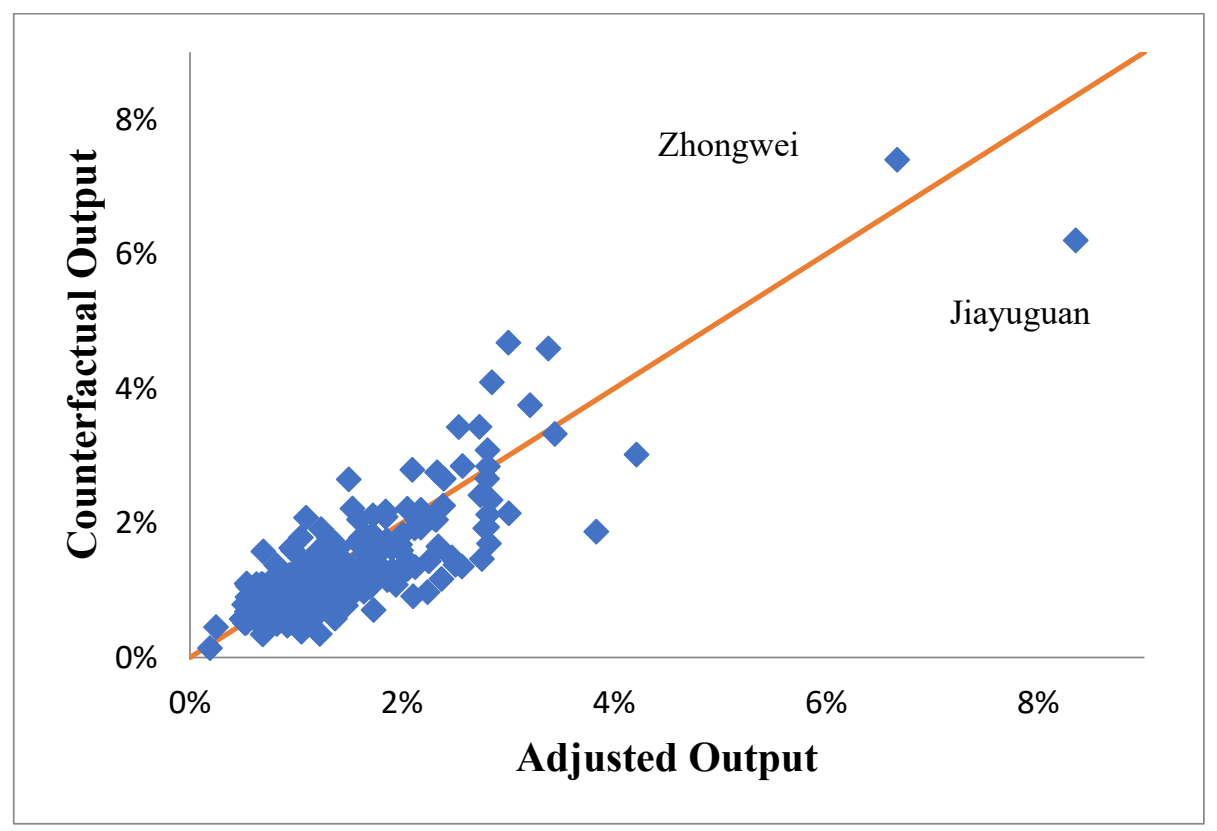

Source: Author's own calculations

Table 4 Counterfactual Output and Adjusted Output - The Effect of Changes in the Spatial Dispersion of Relative Wages by Group

\begin{tabular}{|l|l|}
\hline & 2013 Counterfactual Output \\
\hline 1) All Cities & $25.41 \%$ \\
\hline 2) Coastal Cities & $3.27 \%$ \\
\hline 3) Central Cities & $9.98 \%$ \\
\hline 4) Western Cities & $12.16 \%$ \\
\hline
\end{tabular}

Source: Author's own calculations

Notes: Entries in column 2 are the percentage difference between the counterfactual output level in 2013 and the adjusted output level. 
Table 5 : Robustness - The Effect of Changes in the Spatial Dispersion of Relative Wages under Alternative Labour and Capital Share

\begin{tabular}{|c|c|c|c|}
\hline Counterfactual Output & $\begin{array}{c}\text { (1) } \\
\text { Baseline } \\
\alpha=0.43 \\
\eta=0.39\end{array}$ & $\begin{aligned} & \text { (2) } \\
& \\
\alpha & =0.32 \\
\eta & =0.5\end{aligned}$ & $\begin{array}{c}\text { (3) } \\
\alpha=0.5 \\
\eta=0.32\end{array}$ \\
\hline Coastal Cities $(\mathrm{N}=101)$ & $3.27 \%$ & $2.97 \%$ & $3.55 \%$ \\
\hline Central Cities $(\mathrm{N}=101)$ & $9.98 \%$ & $7.17 \%$ & $11.71 \%$ \\
\hline Western Cities $(\mathrm{N}=\mathbf{8 4})$ & $12.16 \%$ & $9.76 \%$ & $13.9 \%$ \\
\hline
\end{tabular}

Source: Author's own calculations

\subsection{Sources of Wage Dispersion: Housing Supply and Amenities}

Thus far, the results of this paper have shown that increase the spatial dispersion of real wages would lower aggregate growth and aggregate welfare. However, the cause of the increase in wage dispersion, and its implications for welfare, are yet to be considered. According to equation (5), the difference between welfare and output is simply the price of utility, which is estimated by housing price and amenities, so it is important to understand how housing prices amenities affect wage level.

This section examines the two factors - amenities and housing supply restrictions - that have contributed the most to the losses in output. This section only covers a nine-year period, as the housing price data for 286 Chinese cities are only available from 2005 onwards. 


\subsubsection{Amenities}

According to Hsieh and Moretti (2017), the distribution of amenities may differently affect aggregate output growth and it is depending on whether the city's wage is high or low. Wage gap across cities may narrowed if amenities have improved in cities with higher wage level, and therefore increases aggregate output. Equation (2) can be used to measure amenities as follows: $Z_{i}=W_{i} / P_{i}{ }^{\beta}$. This equation indicates that local amenities are equal to the ratio of housing price and real wages, where the weight on housing price, $\beta$, reflects the share of housing expenditures on total expenditures. $\beta$ is estimated to be $0.10 .^{5}$ Some studies follow the quality of life literature to estimates the amenities and used data of the environment (such as $\mathrm{CO}_{2}$ emissions), and other life-quality measures from different city rankings (such as transport, education, arts, recreation, and leisure). As shown in Appendix B, of the seven correlation coefficients between the amenities estimations of this study and these alternative measures, all have the expected sign and two are statistically significant at the 10 per cent level, one is statistically significant at the 5 per cent level, and two are statistically significant at the 1 per cent level.

Figure 8 displays the quantification of the role played by changes in amenities. ${ }^{6}$ The counterfactual output is computed by assuming that the amenity in 2013 is equal to the 2005 . $^{7}$ This counterfactual was calculated in a two-step process. First, equation (4) was used to compute what wages would be in 2013, had amenities in each city stayed at 2005 levels (holding TFP constant). Then, counterfactual output was calculated based on equation (7).

The results indicate that counterfactual output is higher than adjusted output, with more than

\footnotetext{
${ }^{5}$ This study calculates the share of housing in total expenditures of urban households in 2013 using the ratio of national average per capita residence expenditures to cash consumption expenditures. All the data were obtained from the China Statistical Yearbook (2014).

${ }^{6}$ Appendix B shows that the spatial dispersion of amenities has increased between 2005 and 2013.

${ }^{7}$ The housing price data are only available from 2005 for most Chinese cities.
} 
50 per cent of Chinese cities having higher counterfactual than observed output. Most of these are coastal and western cities. The results also show that changes in amenities in those cities between 2005 and 2013 had a positive impact on their growth, although the effect is small. Our estimates also indicate that amenities in western cities improved from 2005 to 2013. Assuming amenities level in 2013 equal to their 2005 levels would further increase wages in the western cities and narrow the wage gap between western cities and national. Amenities in most of the coastal cities have not improved as much as the national average. Therefore, rolling the amenities of coastal cities back to their 2005 levels would further decrease local wages and thus slightly decrease overall wage dispersion.

\section{Figure 8 Counterfactual Output and Adjusted Output - The Effect of Changes in} Amenities

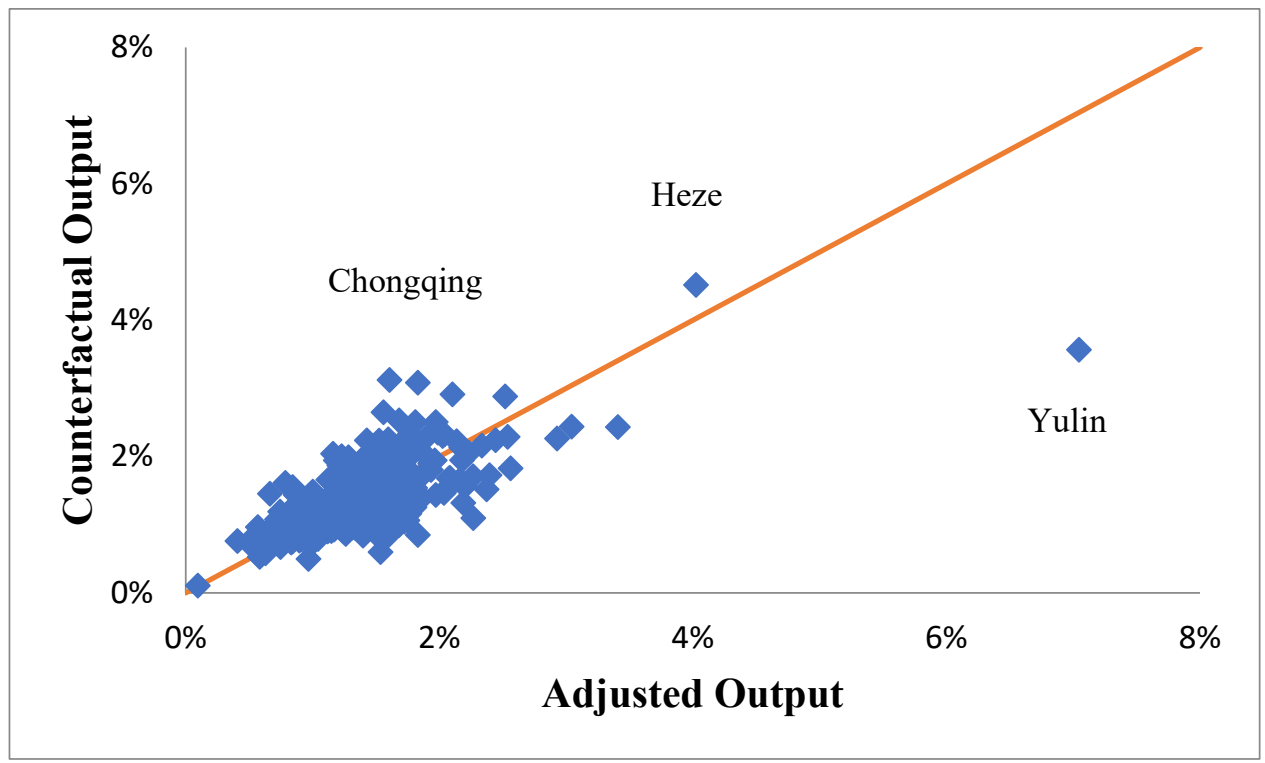

Source: Author's own calculations

Notes: This figure plots the counterfactual output growth, as a percentage, for each city (on the $y$-axis) against the percentage of adjusted output growth of each city (on the x-axis).

In summary, it is possible to conclude that amenities have improved differentially across Chinese cities. However, the overall effect of counterfactual amenities is limited and can only explain a small proportion of the counterfactual output gains. 


\subsubsection{Housing Supply}

Over the past decade, China has experienced an unprecedented surge in house price (Feng and $\mathrm{Wu}$ 2015). Figure 9 plots the average residential house price and sale area in 35 major Chinese cities, which are municipalities, provincial capital cities and quasi-provincial capital cities in China. The average house price in these cities increased from 2,483 yuan per square meter in 2002 to 9,740 yuan per square meter in 2015 , that is, it grew more than four times in 14 years. This represents an average nominal annual growth rate of 11.30 per cent. Figure 10 depicts residential house price to income ratio in China, which is a common measure of housing affordability. ${ }^{8}$ At the national level, this ratio sharply increased from 3.4 in 2005 to 4.4 in 2011 , and gradually declined to 4.3 in 2013 . Over the past decade, urban house prices have been rising faster than income.

Figure 9 Average Nominal Residential House Price and Sales Area in 35 Major Chinese Cities

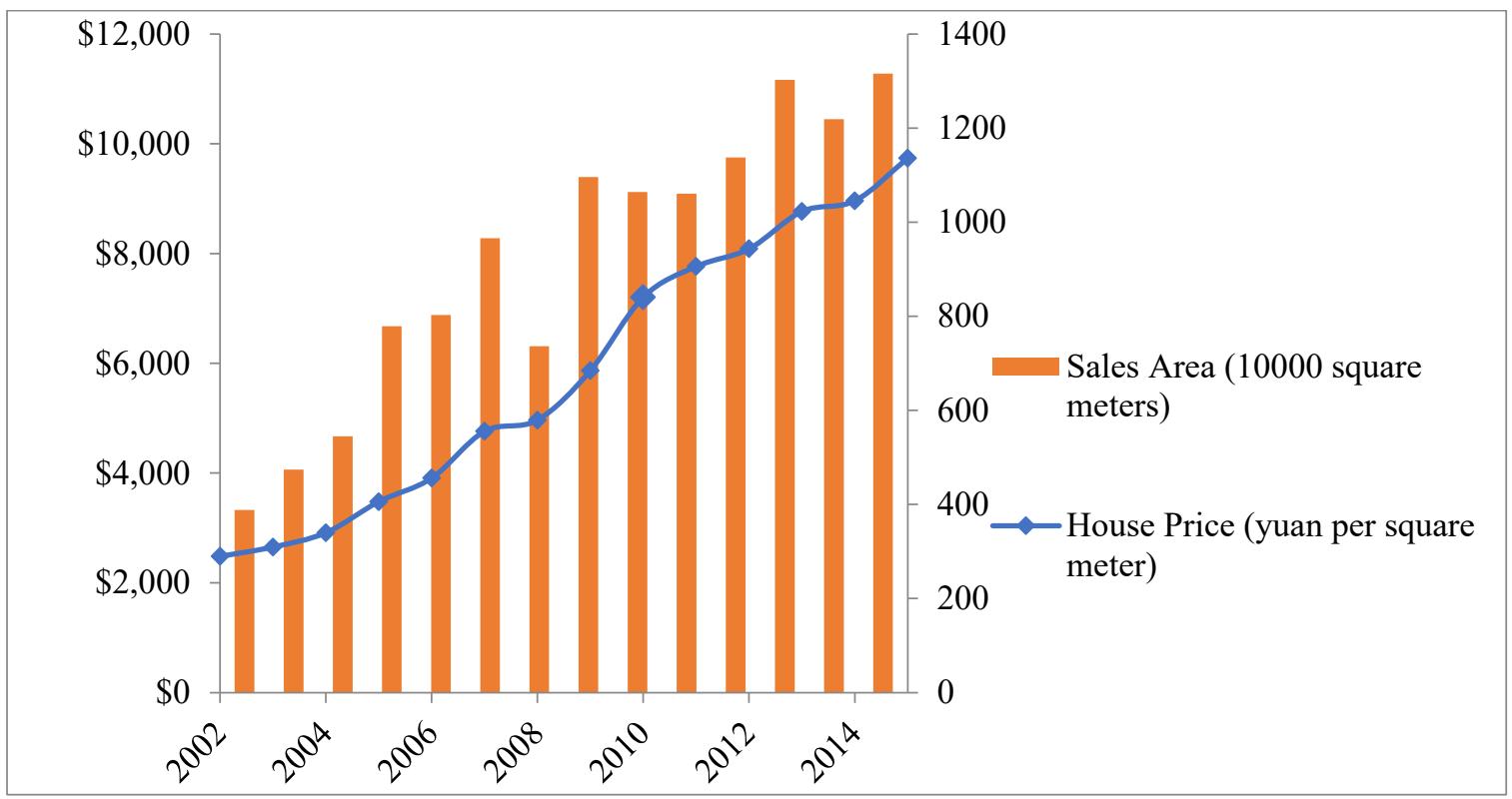

Source: Author's own calculations

\footnotetext{
${ }^{8}$ Urban residential house price to income ratio $=$ (average housing price per square meter/average capita income)*housing size per person. Following (Wu et al., 2012), it assumes that the housing size per person is 30.
} 
Figure 10 China's Residential House Price to Income Ratio, at the National Level

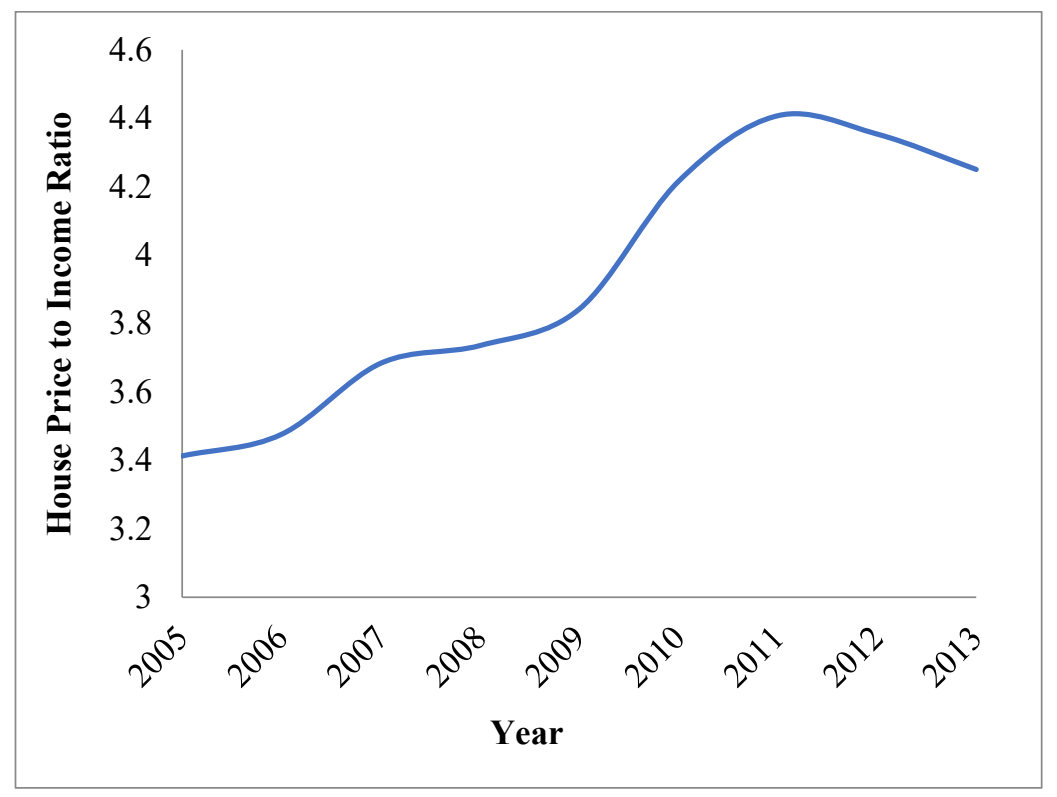

Source: Author's own calculations

In the model, the equilibrium housing price can be expressed as $P_{i}=\left(A_{i} Z_{i}^{1-\eta}\right)^{\frac{\gamma_{i}}{(1-\eta)\left(1-\beta \gamma_{i}\right)-\alpha}}$. This shows that higher local TFP, better amenities, and higher $\gamma_{i}$ result in the higher housing price. Obtaining the relevant counterfactual involves three steps. First, the elasticity of the housing supply is calculated for each Chinese city. ${ }^{9}$ Second, the elasticity is used to estimate the counterfactual housing prices and wages for all Chinese cities, holding local TFP and amenities constant at 2013 levels. The final step is to compute the counterfactual output.

Based on the estimations, Beijing, Tianjin, Harbin, Shanghai, Wuhan, Changsha, Chengdu, Chongqing and Xian have relatively inelastic housing supplies. Conversely, 54 cities have negative elasticity. Notably, all of the aforementioned cities experienced relatively large appreciations in house price but relatively small increases in housing supply during the sample period. This result is consistent with Wang et al. (2012). The mean housing supply elasticity

\footnotetext{
${ }^{9}$ See Appendix D for the calculations.
} 
for the 286 cities is a significant 0.29 . Empirically, the calculation uses counterfactual elasticity to estimate counterfactual wages in Beijing, Tianjin, Harbin, Shanghai, Wuhan, Changsha, Chongqing, Chengdu and Xian. ${ }^{10}$ Accordingly, it is found that counterfactual wages are lower in these nine cities, and labour supply is higher. This is due to when counterfactual housing supply is increased, in equilibrium, more workers can move to these cities from the other regions of China.

The result shown in Table 6 indicates that this counterfactual housing supply would significantly increase the rate of growth. The counterfactual output gain between 2005 and 2013 is 20.92 per cent. Comparing this figure with Table 4 (25.41 per cent), leads to the conclusion that housing supply elasticity accounts for more than 80 per cent of the overall counterfactual output gains.

Table 6 Counterfactual Output - The Effect of Changing Housing Supply Regulations

\begin{tabular}{|c|c|}
\hline & 2013 Counterfactual Output \\
\hline $\begin{array}{l}\text { Elasticity of housing supply in Beijing, Tianjin, } \\
\text { Harbin, Shanghai, Wuhan, Changsha, Chongqing, } \\
\text { Chengdu and Xian are set equal to the mean } \\
\text { regulation level }\end{array}$ & $20.92 \%$ \\
\hline
\end{tabular}

Source: Author's own calculations

Notes: The entry in column 1 is the percentage difference between the counterfactual output level in 2013 and the adjusted output level.

\section{Conclusion}

This paper highlights the possibility of output and welfare losses due to wage dispersion over the past decade. As the estimations are based on a number of untestable assumptions, they

\footnotetext{
${ }^{10}$ It sets the elasticity of housing supply in these listed cities as the national average level.
} 
should not be taken as precise, but rather as an indication of the general order of magnitude of these losses.

The results show that the adjusted contribution of a city to aggregate growth is significantly different from the standard accounting contribution. It is found that most of China's adjusted aggregate growth was driven by the western cities. Although labour productivity and labour demand grew most rapidly in Beijing, Tianjin, Shanghai and Guangzhou, and these cities have a high concentration of service sector such as high-tech and finance, growth in these cities had limited benefits for aggregate Chinese growth. This is likely because fast growth in these cities meant increased local wages and housing prices. Strong labour demand, tight housing supply and high housing prices effectively limited employment. In contrast, the housing supplies of central and western cities were relatively elastic. Therefore, TFP growth in these cities had a small effect on local housing prices and real wages, and lower housing price has a positive effect on local employment.

Land availability and land use regulations may have an effect on the housing supply. It is estimated that lowering regulatory constraints in Beijing, Tianjin, Harbin, Shanghai, Wuhan, Changsha, Chongqing, Chengdu and Xian to the mean level, would increase Chinese GDP by 20.92 per cent over examined period. This suggests that local land use regulations which restrict housing supply have important negative externalities for the country.

One possible way to minimize these negative externalities in high TFP cities would be for the Chinese government to constrain the ability of Chinese cities to set land use regulations. For example, the size of Beijing is around 16,000 square kilometres, yet the urban area is only 2,000 square kilometres. Thus, there is much potential for the development of land outside of the urban area. The government of Beijing could relax land use regulations and increase the housing supply. An alternative option is to further develop public transportation which links 
high productivity and high real wages cities with low productivity and low real wages cities. For example, a vast network of high-speed trains would allow many workers in cities with low TFP and low wages to commute to high TFP and high wage cities. Currently the majority of China's high-speed railway only connects provincial capital cities and municipalities. 


\section{Appendix A: Capital Stock Estimation}

The perpetual inventory method (PIM) is applied to construct the capital stock for each city:

$$
K_{i t}=(1-\delta) K_{i, t-1}+I_{i t} / P_{i t}
$$

where $K_{i, t}$ and $K_{i, t-1}$ are the capital stocks in year $t$ and year $t-1, I_{i t}$ is the investment in fixed assets for city $i$ in year $t, \delta$ is the depreciation rate and $P_{i t}$ is the price deflator for investment in fixed assets. Based on this expression, the following must be obtained: the capital stock value in the base year, that is, 1978; the depreciation rate; the investment in fixed assets; and the price deflator. According to Kohli (1982) and Hall and Jones (1999), the base year capital stock in this study can be calculated as $K=I /\left[P_{i}\left(\delta+g_{i}\right)\right]$, where $g_{i}$ is the average annual growth rate of investment in each city.

Appendix B: Correlation Coefficients between Estimated Amenities and Standard Measures of Amenities

\begin{tabular}{|c|c|c|c|}
\hline & Correlation & P-value & Expected Sign \\
\hline City Road Area & 0.03 & 0.198 & Yes \\
\hline $\begin{array}{c}\text { Number of Buses Per } \\
10 \text { Thousand People }\end{array}$ & 0.01 & 0.633 & Yes \\
\hline $\mathrm{CO}_{2}$ Emissions & -0.05 & 0.022 & Yes \\
\hline $\begin{array}{c}\text { Public Library Per } \\
100 \text { People }\end{array}$ & 0.068 & 0.00 & Yes \\
\hline $\begin{array}{c}\text { Number of Teachers } \\
\text { Number of High } \\
\text { Schools }\end{array}$ & -0.02 & 0.097 & Yes \\
\hline
\end{tabular}




\begin{tabular}{|l|l|l|l|}
\hline Energy Consumption & 0.12 & 0.00 & Yes \\
\hline
\end{tabular}

\section{Appendix C: Amenities in 2005 and 2013}

\begin{tabular}{|l|c|c|c|}
\hline & Std. Dev. & Interquartile & Range \\
& (1) & (2) & (3) \\
\hline Amenities in 2005 & 2501.02 & 2679.06 & 14922 \\
\hline Amenities in 2013 & 3661.61 & 4005.03 & 25358 \\
\hline
\end{tabular}

\section{Appendix D: Estimation of the Elasticity of Housing Supply}

To estimate city-level supply elasticity, sales area is estimated based on housing prices, while controlling for important cost shifters in a panel data model (Wang et al. 2012).

Using the panel data set of 2574 observations (286 cities over 9 years: 2005-2013), the price elasticity of supply is estimated at the city-level using a panel data model (as in Grimes and Aitken, 2010). The equation is as follows:

$$
\ln \left(\text { SaleArea }_{i t}\right)=\gamma_{0}+\gamma_{1} \ln \left(H P_{i t}\right)+\gamma_{2} \ln \left(H P_{i, t-1}\right)+\gamma_{3} \text { MRate }_{i t}+\varepsilon
$$

SaleArea measures the newly sold floor area of residential housing in city $i$ at year $t, H P$ is the housing price level, and MRate is the five-year mortgage interest rate, which is restricted to be identical across cities. ${ }^{11} \gamma_{0}$ is an overall constant term, $\gamma_{1}$ is the price elasticity of supply for city $i$, and $\varepsilon_{i, t}$ is the error term for city $i$ and year $t$. Given the short time series, it is assumed

\footnotetext{
${ }^{11}$ The bank lending mortgage rate, which is modulated by the People's Bank of China, is identical across different regions.
} 
that there are no significant temporal effects and therefore no year fixed effect is included in the model.

Table AD Elasticity of Housing Supply by Cities

\begin{tabular}{|c|c|c|c|c|c|}
\hline City & Elasticity & City & Elasticity & City & Elasticity \\
\hline Ankang & 0.14 & Dongguan & 0.55 & Huizhou & 0.66 \\
\hline Anqing & 0.49 & Dongying & 0.43 & Huludao & 0.33 \\
\hline Anshan & 0.54 & Erdos & 0.52 & Huzhou & 0.29 \\
\hline Anshun & -0.21 & Ezhou & -0.14 & Jiamusi & 0.25 \\
\hline Anyang & 0.59 & Fangchenggang & 0.06 & Jian & 0.38 \\
\hline Baicheng & -0.52 & Foshan & 0.66 & Jiangmen & 0.45 \\
\hline Baise & 0.25 & Fushun & 0.26 & Jiaozuo & 0.35 \\
\hline Baishan & -0.10 & Fuxin & 0.12 & Jiaxing & 0.46 \\
\hline Baiyin & -0.12 & Fuyang & 0.3 & Jiayuguan & -0.03 \\
\hline Baoding & 0.55 & Fuzhou & 0.58 & Jieyang & 0.12 \\
\hline Baoji & 0.37 & Fuzhou & 0.47 & Jilin & 0.65 \\
\hline Baoshan & -1.16 & Ganzhou & 0.59 & Jinan & 0.54 \\
\hline Baotou & 0.62 & Guangan & 0.46 & Jinchang & -0.15 \\
\hline Bayanzhuoer & 0.26 & Guangyuan & -0.06 & Jincheng & -0.21 \\
\hline Bazhong & 0.21 & Guangzhou & 0.75 & Jindezhen & 0.08 \\
\hline Beihai & 0.14 & Guigang & 0.19 & Jinhua & 0.3 \\
\hline Beijing & 0.75 & Guilin & 0.52 & Jining & 0.44 \\
\hline Bengbu & 0.27 & Guiyang & 0.8 & Jinmen & 0.14 \\
\hline Benxi & 0.33 & Guyuan & -0.21 & Jinzhong & 0.17 \\
\hline Binzhou & 0.24 & Haikou & 0.19 & Jinzhou & 0.52 \\
\hline Cangzhou & 0.49 & Hailaer & 0.5 & Jinzhou & 0.21 \\
\hline Changchun & 0.76 & Handan & 0.4 & Jiujiang & 0.47 \\
\hline Changde & 0.52 & Hangzhou & 0.6 & Jiuquan & -0.11 \\
\hline Changsha & 1.05 & Hanzhong & 0.29 & Jixi & -0.2 \\
\hline Changzhi & 0.17 & Haozhou & 0.02 & Kaifeng & 0.19 \\
\hline Changzhou & 0.67 & Harbin & 0.85 & Karamay & -0.75 \\
\hline Chaohu & 0.36 & Hebi & -0.01 & Kunming & 0.92 \\
\hline
\end{tabular}




\begin{tabular}{|c|c|c|c|c|c|}
\hline Chaozhou & -0.14 & Hefei & 0.94 & Laibing & 0.76 \\
\hline Chengde & 0.32 & Hegang & -0.23 & Laiwu & -0.06 \\
\hline Chengdu & 1.21 & Heihe & -0.18 & Langfang & 0.67 \\
\hline Chenzhou & 0.44 & Hengshui & 0.38 & Lanzhou & 0.31 \\
\hline Chifeng & 0.54 & Hengyang & 0.51 & Leshan & 0.35 \\
\hline Chizhou & 0.1 & Heyuan & 0.09 & Lianyungang & 0.56 \\
\hline Chongqing & 1.56 & Heze & 0.45 & Liaocheng & 0.25 \\
\hline Chongzuo & 0.07 & Hezhou & -0.3 & Liaoyang & 0.23 \\
\hline Chuzhou & 0.39 & Hezhou & -0.09 & Liaoyuan & -0.04 \\
\hline Dalian & 0.78 & Hohhot & 0.55 & Lijiang & -0.46 \\
\hline Dandong & 0.49 & Huaian & 0.67 & Lincang & -0.44 \\
\hline Daqing & 0.51 & Huaibei & 0.06 & Linfen & -0.03 \\
\hline Datong & 0.002 & Huaihua & 0.44 & Linxi & 0.54 \\
\hline Dazhou & 0.48 & Huainan & 0.2 & Lishui & -0.22 \\
\hline Deyang & 0.34 & Huanggang & 0.35 & Liuan & 0.27 \\
\hline Dezhou & 0.4 & Huangshan & 0.14 & Liupanshui & 0.09 \\
\hline Dingxi & -0.25 & Huangshi & 0.16 & Liuzhou & 0.46 \\
\hline Longnan & -1.02 & Shanghai & 0.97 & Wuhu & 0.39 \\
\hline Longyan & 0.09 & Shangluo & -0.33 & Wulanchabu & 0.23 \\
\hline Loudi & 0.38 & Shangqiu & 0.49 & Wuwei & -0.69 \\
\hline Luliang & -0.13 & Shangrao & 0.43 & Wuxi & 0.68 \\
\hline Luohe & 0.21 & Shantou & 0.13 & Wuzhong & 0.05 \\
\hline Luoyang & 0.69 & Shanwei & -0.26 & Wuzhou & 0.14 \\
\hline Luzhou & 0.53 & Shaoguan & 0.39 & Xiamen & 0.19 \\
\hline Maanshan & 0.27 & Shaoxing & 0.39 & Xian & 0.99 \\
\hline Maoming & 0.36 & Shaoyang & 0.23 & Xiangfan & 0.49 \\
\hline Meishan & 0.38 & Shenyang & 1.13 & Xiangtan & 0.38 \\
\hline Meizhou & 0.16 & Shenzhen & 0.25 & Xianning & 0.26 \\
\hline Mianyang & 0.5 & Shijiazhuang & 0.7 & Xianyang & 0.19 \\
\hline Mudanjiang & 0.29 & Shiyan & 0.25 & Xiaogan & 0.27 \\
\hline Nanchang & 0.63 & Shizuishan & 0.09 & Xining & 0.27 \\
\hline Nanchong & 0.59 & Shuangyashan & -0.22 & Xinshe & 0.22 \\
\hline
\end{tabular}




\begin{tabular}{|c|c|c|c|c|c|}
\hline Nanjing & 0.75 & Simao & -0.66 & Xintai & 0.36 \\
\hline Nanning & 0.71 & Siping & 0.23 & Xinxiang & 0.67 \\
\hline Nanping & 0.23 & Songyuan & 0.085 & Xinyang & 0.69 \\
\hline Nantong & 0.72 & Suihua & 0.51 & Xinzhou & 0.03 \\
\hline Nanyang & 0.58 & Suining & 0.45 & Xuancheng & 0.35 \\
\hline Neijiang & 0.4 & Suizhou & 0.08 & Xuchang & 0.37 \\
\hline Ningbo & 0.42 & Suqian & 0.76 & Xuzhou & 0.7 \\
\hline Ningde & 0.04 & Suzhou & 0.003 & Yaan & -0.36 \\
\hline Panjing & 0.25 & Suzhou & 0.92 & Yanan & -0.32 \\
\hline Panzhihua & 0.05 & Suzhou & 0.27 & Yancheng & 0.65 \\
\hline Pingdingshan & 0.25 & Taian & 0.22 & Yangjiang & 0.15 \\
\hline Pingliang & -0.26 & Taiyuan & 0.21 & Yangquan & 0.09 \\
\hline Pinxiang & -0.12 & Taizhou & 0.49 & Yangzhou & 0.6 \\
\hline Putian & 0.01 & Taizhou & 0.25 & Yantai & 0.67 \\
\hline Puyang & 0.26 & Tangshan & 0.61 & Yibing & 0.47 \\
\hline Qindao & 0.79 & Tianjin & 0.95 & Yichang & 0.38 \\
\hline Qinghuangdao & 0.31 & Tianshui & -0.07 & Yichun & -0.18 \\
\hline Qingyang & -0.38 & Tieling & 0.52 & Yichun & 0.5 \\
\hline Qinyuan & 0.44 & Tongchuan & -0.21 & Yinchuan & 0.6 \\
\hline Qinzhou & 0.11 & Tonghua & 0.28 & Yingkou & 0.63 \\
\hline Qiqihar & 0.38 & Tongliao & 0.31 & Yintan & -0.29 \\
\hline Qitaihe & -0.27 & Tonglin & -0.16 & Yiyang & 0.45 \\
\hline Quanzhou & 0.48 & Urumqi & 0.59 & Yongzhou & 0.55 \\
\hline Qujing & -0.38 & Weifang & 0.79 & Yueyang & 0.49 \\
\hline Quzhou & 0.04 & Weihai & 0.59 & Yulin & 0.28 \\
\hline Rizhao & 0.2 & Weinan & 0.35 & Yulin & -0.19 \\
\hline Sanmenxia & -0.01 & Wenzhou & -0.05 & Yuncheng & 0.42 \\
\hline Sanming & 0.19 & Wuhai & 0.15 & Yunfu & -0.14 \\
\hline Sanya & -0.27 & Wuhan & 0.92 & Yuxi & -0.1 \\
\hline Zaozhuang & 0.27 & Zhaotong & -0.62 & Zhoushan & -0.23 \\
\hline Zhangjiajie & -0.11 & Zhaoyang & 0.56 & Zhuhai & 0.11 \\
\hline Zhangjiakou & 0.7 & Zhengzhou & 0.99 & Zhumadian & 0.67 \\
\hline
\end{tabular}




\begin{tabular}{|cccccc|}
\hline Zhangye & -0.14 & Zhenjiang & 0.46 & Zhuzhou & 0.71 \\
\hline Zhangzhou & 0.41 & Zhongshan & 0.62 & Zibo & 0.67 \\
\hline Zhanjiang & 0.13 & Zhongwei & -0.14 & Zigong & 0.34 \\
\hline Zhaoqin & 0.38 & Zhoukou & 0.54 & Ziyang & 0.52 \\
\hline
\end{tabular}

\section{Appendix E: Derivation of Equations}

According to equation (1)

$$
\begin{aligned}
& Y_{i}=A_{i} L_{i}^{\alpha} K_{i}^{\eta} \\
& \frac{\partial Y_{i}}{\partial L_{i}}=\alpha A_{i} L_{i}^{\alpha-1} K_{i}^{\eta} \\
& \frac{\partial Y_{i}}{\partial K_{i}}=\eta A_{i} L_{i}^{\alpha} K_{i}^{\eta-1}
\end{aligned}
$$

In equilibrium, $\frac{\partial Y_{i}}{\partial L_{i}}=W_{i}$ and $\frac{\partial Y_{i}}{\partial K_{i}}=R_{i}$, where $W_{i}$ is the wage rate and $R_{i}$ is the interest rate.

$$
\begin{gathered}
\alpha A_{i} L_{i}^{\alpha-1} K_{i}^{\eta}=W_{i} \\
\eta A_{i} L_{i}^{\alpha} K_{i}^{\eta-1}=R_{i} \\
\alpha A_{i} L_{i}^{\alpha} K_{i}^{\eta}=W_{i} L_{i} \\
\eta A_{i} L_{i}^{\alpha} K_{i}^{\eta}=R_{i} K_{i} \\
\frac{\alpha}{\eta}=\frac{W_{i} L_{i}}{R_{i} K_{i}}
\end{gathered}
$$




$$
\begin{aligned}
& K_{i}=\eta \frac{W_{i} L_{i}}{R_{i} \alpha} \\
& \alpha A_{i} L_{i}^{\alpha-1}\left(\eta \frac{W_{i} L_{i}}{R_{i} \alpha}\right)^{\eta}=W_{i} \\
& \alpha^{1-\eta} A_{i} L_{i}^{\alpha+\eta-1}=R_{i}^{\eta} \eta^{-\eta} W_{i}^{1-\eta} \\
& \frac{\alpha^{1-\eta} R_{i}^{-\eta} \eta^{\eta} A_{i}}{W_{i}^{1-\eta}}=L_{i}^{1-\alpha-\eta} \\
& L_{i}=\left(\alpha^{1-\eta} R_{i}^{-\eta} \eta^{\eta}\right)^{\frac{1}{1-\alpha-\eta}}\left(\frac{A_{i}}{W_{i}^{1-\eta}}\right)^{\frac{1}{1-\alpha-\eta}} \\
& \delta_{i}=\left(\alpha^{1-\eta} \frac{\eta}{R_{i}}\right)^{\frac{1}{1-\alpha-\eta}}=\left(\frac{\eta \alpha^{1-\eta}}{R_{i}}\right)^{\frac{1}{1-\alpha-\eta}} \\
& V=\frac{W_{i} Z_{i}}{P_{i}^{\beta}}(1.2) \\
& W_{i}=\frac{V P_{i}^{\beta}}{Z_{i}} \\
& W_{i}^{1-\eta}=\left(\frac{V P_{i}^{\beta}}{Z_{i}}\right)^{1-\eta} \\
& \frac{1}{W_{i}^{1-\eta}}=\frac{Z_{i}^{1-\eta}}{V P_{i}^{\beta(1-\eta)}} \\
& L_{i}=\delta_{i}\left(\frac{A_{i} Z_{i}^{1-\eta}}{V P_{i}^{\beta(1-\eta)}}\right)^{\frac{1}{1-\alpha-\eta}}=\delta_{i} V^{-\frac{1}{1-\alpha-\eta}}\left(\frac{A_{i} Z_{i}^{1-\eta}}{P_{i}^{\beta(1-\eta)}}\right)^{\frac{1}{1-\alpha-\eta}}
\end{aligned}
$$

Assume $P_{i}=L_{i}^{\gamma_{i}}$ 


$$
\begin{gathered}
W_{i}=\frac{V P_{i}^{\beta}}{Z_{i}}=\frac{V L_{i}^{\gamma_{i} \beta}}{Z_{i}} \\
=\frac{V}{Z_{i}}\left[\left(\delta_{i}\left(\frac{A_{i}}{W_{i}^{1-\eta}}\right)^{\frac{1}{1-\alpha-\eta}}\right]^{\gamma_{i} \beta}\right. \\
W_{i}=V \delta_{i}^{\gamma_{i} \beta} \frac{A_{i}^{\frac{\gamma_{i} \beta}{1-\alpha-\eta}}}{Z_{i} W_{i}^{\frac{\gamma_{i} \beta(1-\eta)}{1-\alpha-\eta}}} \\
=\left(V \delta_{i}^{\gamma_{i} \beta}\right)^{\frac{1}{(1-\eta)\left(1+\beta \gamma_{i}\right)-\alpha}}\left(\frac{A_{i}^{\beta \gamma_{i}}}{Z_{i}^{1-\alpha-\eta}}\right)^{\frac{1}{(1-\eta)\left(1+\beta \gamma_{i}\right)-\alpha}}
\end{gathered}
$$

$$
\begin{gathered}
V=\frac{W_{i} Z_{i}}{P_{i}^{\beta}} \\
=\frac{Y_{i}}{L_{i}} \frac{Z_{i}}{P_{i}^{\beta}} \\
\frac{Y_{i} Z_{i}}{L_{i} P_{i}^{\beta}}=V \\
Y_{i}=V L_{i} \frac{P_{i}^{\beta}}{Z_{i}} \\
\sum Y_{i}=Y=V \sum^{L_{i}} \frac{P_{i}^{\beta}}{Z_{i}} \\
V=Y\left(\sum L_{i} \frac{P_{i}^{\beta}}{Z_{i}}\right)^{-1}
\end{gathered}
$$




$$
\begin{aligned}
& L_{i}=\delta\left(\frac{A_{i}}{W_{i}^{1-\eta}}\right)^{\frac{1}{1-\alpha-\eta}} \\
& =\delta A_{i}^{\frac{1}{1-\alpha-\eta}}\left(\frac{1}{W_{i}}\right)^{\frac{1-\eta}{1-\alpha-\eta}} \\
& =\delta A_{i}^{\frac{1}{1-\alpha-\eta}}\left(\frac{\bar{W}}{W_{i}}\right)^{\frac{1-\eta}{1-\alpha-\eta}} \bar{W}^{-\frac{1-\eta}{1-\alpha-\eta}} \\
& \bar{W}^{\frac{1-\eta}{1-\alpha-\eta}} L_{i}=\delta A_{i}^{\frac{1}{1-\alpha-\eta}}\left(\frac{\bar{W}}{W_{i}}\right)^{\frac{1-\eta}{1-\alpha-\eta}} \\
& \bar{W}^{\frac{1-\eta}{1-\alpha-\eta}} \sum L_{i}=\delta \sum A_{i}^{\frac{1}{1-\alpha-\eta}}\left(\frac{\bar{W}}{W_{i}}\right)^{\frac{1-\eta}{1-\alpha-\eta}} \\
& \bar{W}=\sum W_{i} L_{i}=\alpha \sum Y_{i}=\alpha Y \\
& (\alpha Y)^{\frac{1-\eta}{1-\alpha-\eta}}=\delta \sum A_{i}^{\frac{1}{1-\alpha-\eta}}\left(\frac{\bar{W}}{W_{i}}\right)^{\frac{1-\eta}{1-\alpha-\eta}} \\
& Y=\frac{\delta_{i}^{\frac{1-\alpha-\eta}{1-\eta}}}{\alpha}\left(\sum A_{i}^{\frac{1}{1-\alpha-\eta}}\left(\frac{\bar{W}}{W_{i}}\right)^{\frac{1-\eta}{1-\alpha-\eta}}\right)^{\frac{1-\alpha-\eta}{1-\eta}}
\end{aligned}
$$




$$
\begin{aligned}
& \frac{Y_{t+1}}{Y_{t}}=\frac{\left[\sum A_{i, t+1}^{\frac{1}{1-\alpha-\eta}}\left(\frac{\bar{W}_{t+1}}{W_{i, t+1}}\right)^{\frac{1-\eta}{1-\alpha-\eta}}\right]^{\frac{1-\alpha-\eta}{1-\eta}}}{\left[\sum A_{i, t}^{\frac{1}{1-\alpha-\eta}}\left(\frac{\bar{W}_{t}}{W_{i, t}}\right)^{\frac{1-\eta}{1-\alpha-\eta}}\right]^{\frac{1-\alpha-\eta}{1-\eta}}}
\end{aligned}
$$

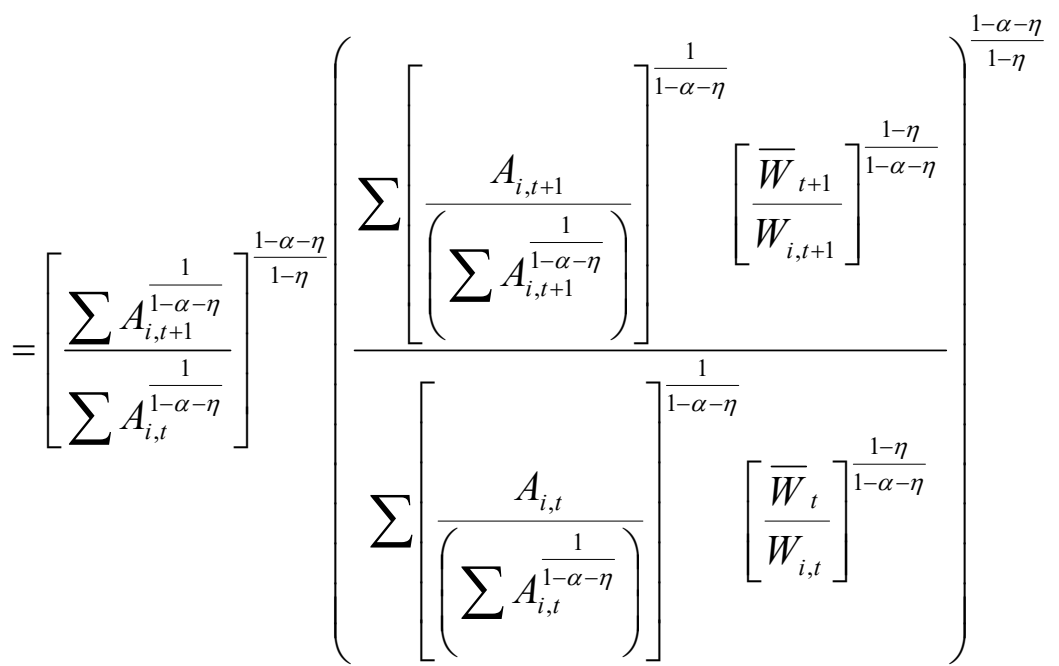

$$
\begin{aligned}
& =\left[\frac{\sum A_{i, t+1}^{\frac{1}{1-\alpha-\eta}}}{\sum A_{i, t}^{\frac{1}{1-\alpha-\eta}}}\right]^{\frac{1-\alpha-\eta}{1-\eta}}\left(\frac{\sum S_{i, t+1}\left[\frac{\bar{W}_{t+1}}{W_{i, t+1}}\right]^{\frac{1-\eta}{1-\alpha-\eta}}}{\sum S_{i, t}\left[\frac{\bar{W}_{t}}{W_{i, t}}\right]^{\frac{1-\eta}{1-\alpha-\eta}}}\right)^{\frac{1-\alpha-\eta}{1-\eta}}
\end{aligned}
$$

$$
S_{i}=\frac{A_{i}^{\frac{1}{1-\alpha-\eta}}}{\sum A_{i}^{\frac{1}{1-\alpha-\eta}}}
$$




\section{Reference List}

Ahlfeldt, G. M., Redding. S. J., Sturm, D. M and Wolf, N. (2015) "The Economics of Density: Evidence from the Berlin Wall." Econometrica 83(6): 2127-2189.Au, C.C. and Henderson, J.V. (2006) “Are Chinese Cities too Small?" The Review of Economic Studies 73(3): 549-576.

Alonso, W. 1964. Location and Land use: Toward a General Theory of Land Rent. Harvard University Press.

Barro, R. J., Martin, S. X., Blanchard, O. J and Hall, R. E. (1991) "Convergence across States and Regions.” Brookings Papers on Economic Activity 1991 (1): 107-182.Barro, R.J. and Martin. S. IX. (1992) “Convergence.” Journal of Political Economy 100(2): 223251.

CCSY (various years). China City Statistical Yearbook. Beijing: China Statistics Press.

Chatterjee, S. and Carlino, G.A. (2001) “Aggregate Metropolitan Employment Growth and the Deconcentration of Metropolitan Employment." Journal of Monetary Economics 48(3): $549-583$.

Chauvin, J.P., Glaeser, E., Ma, Y. and Tobio, K. (2016) "What is Different about Urbanization in Rich and Poor Countries? Cities in Brazil, China, India and the United States.” Journal of Urban Economics 98(2017): 17-49.

CSY (various). China Statistical Yearbook. Beijing: China Statistical Press.

Desmet, K. and Rossi-Hansberg, E. (2013) "Urban Accounting and Welfare." The American Economic Review 103(6): 2296-2327. 
Diamond., R. (2014) “Housing Supply Elasticity and Rent Extraction by State and Local Governments." Stanford University.

Grimes, A. and Aitken, A. (2010) "Housing Supply, Land Costs and Price Adjustment." Real Estate Economics 38(2): 325-353.

Gennaioli, N., Porta, R.L., Lopez-de-Silanes, F. and Shleifer, A. (2013) "Human Capital and Regional Development” (No. w17158). National Bureau of Economic Research.

Feng, Q and Wu, G. L. (2015) "Bubble or Riddle? An Asset-pricing Approach Evaluation on China's Housing Market.” Economic Modelling 46 (2015): 376-383.Glaeser, E.L., Gyourko, J. and Saks, R. (2005). "Why is Manhattan so Expensive? Regulation and the Rise in Housing Prices.” Journal of Law and Economics 48(2): 331-369.

Glaeser, E. L and Gyourko, J. (2005) "Urban Decline and Durable Housing." Journal of Political Economy 113(2): 345-375.

Hall, R. E and Jones, C. I. (1999) "Why do Some Countries Produce so Much More Output per Worker than Others?" The Quarterly Journal of Economics 114(1): 83-116.Hsieh, C.T. and Moretti, E. (2015) "Why Do Cities Matter? Local Growth and Aggregate Growth" (No. w21154). National Bureau of Economic Research.

Kohli, U. (1982) "Production Theory, Technological Change, and the Demand for Imports." European Economic Review 18(2): 369-386.

Muth, R.F. 1969. Cities and Housing. University of Chicago Press.Roback, J. (1982) "Wages, Rents, and the Quality of Life.” The Journal of Political Economy 90(6): 1257-1278.

Rappaport, J. (2007) "Moving to Nice Weather." Regional Science and Urban Economics 37(3): 375-398. 
Redding, S.J. and Sturm, D.M. (2008) "The Costs of Remoteness: Evidence from German Division and Reunification." The American Economic Review 98(5): 1766-1797.

Redding, S.J. (2016) “Goods Trade, Factor Mobility and Welfare.” Journal of International Economics 101(2016): 148-167.

Ren, Y., Xiong, C and Yuan, Y. (2012) "House Price Bubbles in China." China Economic Review 23(4): 786-800.Rosen, S. (1979) "Wage-Based Indexes of Urban Quality of Life." Current Issues in Urban Economics 3.

Roback, J. (1982) "Wages, Rents, and the Quality of Life." Journal of Political Economy 90(6): 1257-1278.

Rosen, S. (1979) "Wage-based Indexes of Urban Quality of Life," in Current Issues in Urban Economics, edited by P. Mieszkowski and M. Straszheim. Baltimore: Johns Hopkins Press, pp. 74-104.

Saiz, A. (2010) “The Geographic Determinants of Housing Supply.” The Quarterly Journal of Economics 125(3): 1253-1296.

Wang, S., S. H., Chan and B, Xu. (2012) "The Estimation and Determinants of the Price Elasticity of Housing Supply: Evidence from China.” Journal of Real Estate Research 34(3): 311-344.

Wu, J., Gyourko, J and Deng, Y. (2012) "Evaluating Conditions in Major Chinese Housing Markets." Regional Science and Urban Economics, 42(3): 531-543.

Wu, Y. (2001) "Is China's Economic Growth Sustainable? A Productivity Analysis." China Economic Review 11(3): 278-296. 
Zhu, X. (2012) “Understanding China's Growth: Past, Present, and Future.” The Journal of Economic Perspectives 26(4): 103-124. 